\title{
Pathways to sustaining tuna-dependent Pacific Island economies during climate change
}

\author{
Johann D. Bell $\mathbb{1}^{1,2} \llbracket$, Inna Senina $\mathbb{D}^{3}$, Timothy Adams $\mathbb{B}^{2,4}$, Olivier Aumont ${ }^{5}$, Beatriz Calmettes ${ }^{3}$, \\ Sangaalofa Clark ${ }^{6}$, Morgane Dessert ${ }^{7,8}$, Marion Gehlen ${ }^{(10}{ }^{9}$, Thomas Gorgues ${ }^{7}$, John Hampton ${ }^{10}{ }^{10}$, \\ Quentin Hanich ${ }^{2}$, Harriet Harden-Davies ${ }^{2}$, Steven R. Hare ${ }^{10}$, Glen Holmes ${ }^{11}$, Patrick Lehodey ${ }^{3}$, \\ Matthieu Lengaigne ${ }^{5}{ }^{5,12}$, William Mansfield ${ }^{13}$, Christophe Menkes ${ }^{10}{ }^{14}$, Simon Nicol ${ }^{10,15}$, \\ Yoshitaka Ota ${ }^{16}$, Coral Pasisi ${ }^{17}$, Graham Pilling ${ }^{10}$, Chis Reid ${ }^{18}$, Espen Ronneberg ${ }^{19}$, Alex Sen Gupta ${ }^{20}$, \\ Katherine L. Seto ${ }^{2,21}$, Neville Smith ${ }^{10}$, Sue Taei ${ }^{1,22}$, Martin Tsamenyi ${ }^{2}$ and Peter Williams ${ }^{10}$
}

\begin{abstract}
Climate-driven redistribution of tuna threatens to disrupt the economies of Pacific Small Island Developing States (SIDS) and sustainable management of the world's largest tuna fishery. Here we show that by 2050 , under a high greenhouse gas emissions scenario (RCP 8.5), the total biomass of three tuna species in the waters of ten Pacific SIDS could decline by an average of $13 \%$ (range $=-5 \%$ to $-20 \%$ ) due to a greater proportion of fish occurring in the high seas. The potential implications for Pacific Island economies in 2050 include an average decline in purse-seine catch of $20 \%$ (range $=-10 \%$ to $-30 \%)$, an average annual loss in regional tuna-fishing access fees of US\$90 million (range $=-$ US $\$ 40$ million to - US $\$ 140$ million) and reductions in government revenue of up to $13 \%$ (range $=-8 \%$ to $-17 \%$ ) for individual Pacific SIDS. Redistribution of tuna under a lower-emissions scenario (RCP 4.5) is projected to reduce the purse-seine catch from the waters of Pacific SIDS by an average of only $3 \%$ (range $=-12 \%$ to $+9 \%$ ), indicating that even greater reductions in greenhouse gas emissions, in line with the Paris Agreement, would provide a pathway to sustainability for tuna-dependent Pacific Island economies. An additional pathway involves Pacific SIDS negotiating within the regional fisheries management organization to maintain the present-day benefits they receive from tuna, regardless of the effects of climate change on the distribution of the fish.
\end{abstract}

\begin{abstract}
ishing for tuna plays a vital role in the economic development and/or food security of most of the 22 Pacific Island countries and territories ${ }^{1,2}$. However, in the case of ten of these Pacific Small Island Developing States (SIDS), the contributions of tuna to the economy are so substantial that these SIDS are 'tuna-dependent' (Fig. 1 and Supplementary Note 1). More than $95 \%$ of all tuna caught from the jurisdictions of the 22 Pacific Island countries and territories comes from the combined exclusive economic zones (EEZs) of these 10 SIDS (Supplementary Table 1), and access fees paid by industrial fishing fleets provide an average of $37 \%$ (range $=4-84 \%$ ) of their government revenue (excluding grants) (Supplementary Table 2). These extraordinary benefits have been secured mainly through cooperative management of the purse-seine fishery within the combined EEZs of nine of the ten Pacific SIDS under the Parties to the Nauru Agreement (PNA) Vessel Day Scheme (VDS) (Box 1). Longline and pole-and-line fishing also occur within the waters
\end{abstract}

of tuna-dependent Pacific SIDs but generally make minor contributions to these economies compared with purse-seine fishing (Supplementary Note 1).

The socioeconomic importance of tuna has been recognized by Pacific Islands Leaders in their Regional Roadmap for Sustainable Pacific Fisheries ${ }^{3}$, which aims to sustain harvests, add value to catches, increase employment associated with tuna fishing and processing, and allocate more tuna for local food security. The Roadmap's sustainability goal is being achieved; over the past decade, annual purse-seine catches from the EEZs of the ten Pacific SIDS have deviated little from the ten-year average of 1.4 million tonnes (Supplementary Table 3) (coefficient of variation $=9 \%$ ) and are approximately half as variable as catches from high-seas areas (Supplementary Table 4) (coefficient of variation $=17 \%$ ). In addition, none of the tuna species caught by purse-seine in the region are overfished or subject to overfishing ${ }^{4}$, due largely to cooperative

\footnotetext{
${ }^{1}$ Center for Oceans, Conservation International, Arlington, VA, USA. ${ }^{2}$ Australian National Centre for Ocean Resources and Security (ANCORS), University of Wollongong, Wollongong, New South Wales, Australia. ${ }^{3}$ Collecte Localisation Satellite, Toulouse, France. ${ }^{4}$ Gonedau Foundation, Port Ouenghi, New Caledonia. ${ }^{5} \mathrm{LOCEAN-IPSL}$, IRD/Sorbonne Universités/CNRS/MNHN, Paris, France. ${ }^{6}$ Parties to the Nauru Agreement Office, Majuro, Marshall Islands. 7Univ. Brest, CNRS, IRD, Ifremer, Laboratoire d'Océanographie Physique et Spatiale (LOPS), IUEM, Brest, France. ${ }^{8}$ Université de Bretagne Occidentale, Brest, France. ${ }^{~}$ LSCE-IPSL, CEA/CNRS/ Université Paris-Saclay, Gif-sur-Yvette, France. ${ }^{10}$ Fisheries, Aquaculture and Marine Ecosystems Division, The Pacific Community (SPC), Noumea, New Caledonia. "'The Pew Charitable Trusts, Brisbane, Queensland, Australia. ${ }^{12}$ MARBEC, Université Montpellier, CNRS, Ifremer, IRD, Sète, France. ${ }^{13}$ Paekakariki, Wellington, New Zealand. ${ }^{14}$ ENTROPIE, IRD/Université de la Réunion/Université de Nouvelle-Calédonie/ CNRS, Ifremer, Noumea, New Caledonia. ${ }^{15}$ Centre for Conservation Ecology and Genomics, Institute for Applied Ecology, University of Canberra, Bruce, Australian Capital Territory, Australia. ${ }^{16}$ School of Marine and Environmental Affairs, University of Washington, Seattle, WA, USA. ${ }^{17}$ Office of the Director General, The Pacific Community (SPC), Noumea, New Caledonia. ${ }^{18}$ Pacific Islands Forum Fisheries Agency, Honiara, Solomon Islands. ${ }^{19}$ Secretariat of the Pacific Regional Environment Programme, Apia, Samoa. ${ }^{20} \mathrm{Climate}$ Change Research Centre and ARC Centre of Excellence for Climate Extremes, University of NSW, Kensington, New South Wales, Australia. ${ }^{21}$ Environmental Studies Department, University of California at Santa Cruz, Santa Cruz, CA, USA.

22Deceased: Sue Taei. 凶e-mail: jbell@conservation.org
} 


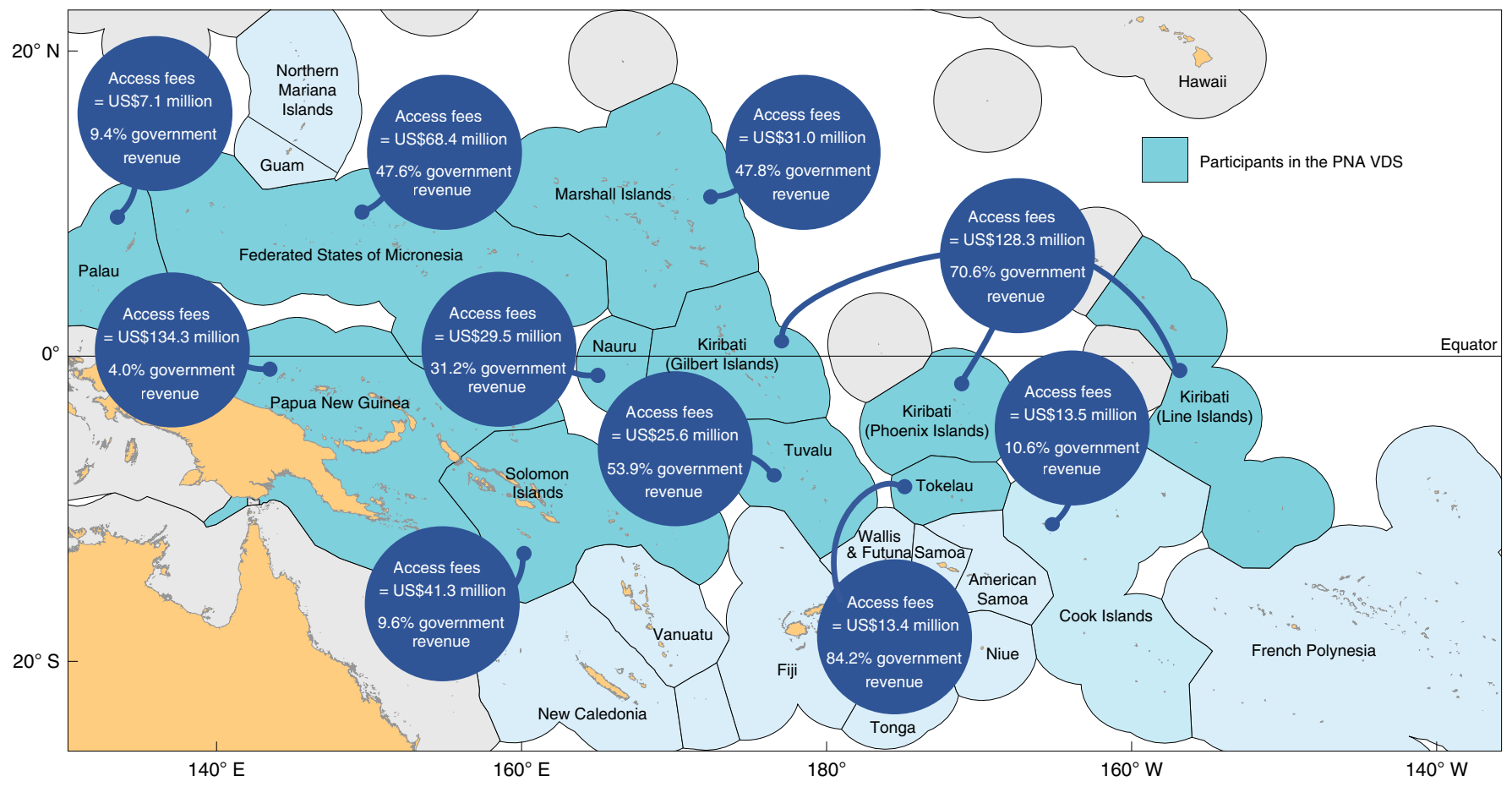

Fig. 1 | Tuna-dependent Pacific SIDS in the western and central Pacific Ocean. Average annual tuna-fishing access fees (US\$) for the period 2015-2018 earned by the ten Pacific SIDS, together with the average percentage contributions of access fees to total government revenue (excluding grants). The nine Pacific SIDS participating in the PNA VDS (Box 1) are also shown. Access fee and government revenue data sourced from ref. ${ }^{1}$ and the Pacific Islands Forum Fisheries Agency.

management by PNA members (Box 1) (Supplementary Notes 3 and 4) under the auspices of the Western and Central Pacific Fisheries Commission (WCPFC).

Cooperative management of the purse-seine fishery has also enabled tuna-dependent economies to adapt to the profound effects of the El Niño-Southern Oscillation (ENSO) on the extent of the western Pacific warm pool ('warm pool') and the associated distribution of the abundant skipjack tuna ${ }^{5,6}$ (Box 1). However, the realization that climate change will alter the tropical Pacific Ocean, and cause further modifications to $\mathrm{ENSO}^{7,8}$ and the warm pool (Supplementary Note 5), has prompted the regional organizations assisting Pacific SIDS to manage their tuna resources, the Pacific Community, Pacific Islands Forum Fisheries Agency and WCPFC, to support modelling of the effects of climate change on tuna biomass $^{9-12}$. This modelling, which focused mainly on the EEZs of Pacific SIDS, projected progressive redistribution of tuna biomass in equatorial waters to the east and, to a more modest extent, to higher latitudes. Provided tuna biomass remains high within the combined EEZs of PNA participants, the provisions of the VDS (Box 1) are expected to limit the implications of climate-driven tuna redistribution for tuna-dependent economies and the goals of the Roadmap.

However, many Pacific SIDS are increasingly concerned that redistribution to the east could lead to decreases in tuna biomass within their EEZs, and increases in high-seas areas, undermining the socioeconomic benefits they derive from tuna fishing (Supplementary Note 6) and the strong management of tropical Pacific tuna resources. Preliminary analyses justify these concerns $^{13,14}$. Here, we evaluate the risks to the sustainability of the ten tuna-dependent Pacific Island economies by simulating changes to tuna biomass in their EEZs and in high-seas areas in the western and central Pacific Ocean (WCPO) and eastern Pacific Ocean (EPO) under different greenhouse gas (GHG) emissions scenarios by 2050 , using a more-robust modelling approach than in previous studies. Our analysis then cascades the results of the biomass modelling to assess the potential implications for future purse-seine catches within the EEZs of the ten Pacific SIDS and for the vital government revenue flowing to these highly vulnerable states from purse-seine fishing. Finally, the projected patterns of tuna redistribution are used to identify the most promising pathways for enabling tuna-dependent economies to retain the socioeconomic benefits they now receive from tuna.

\section{Projected changes in tuna biomass}

We used the Spatial Ecosystem and Population Dynamics Model $(S E A P O D Y M)^{15-17}$, informed by projected changes to the tropical Pacific Ocean derived from four Earth system models (ESMs), to simulate the responses of tuna species caught by purse-seine fishing (skipjack, yellowfin and bigeye tuna) to climate change. SEAPODYM simulates the spatial dynamics of tuna under the effects of fishing and key environmental variables (temperature, primary production, oceanic currents and dissolved oxygen) and the predicted distributions of tuna prey in three layers of the water column between the surface and a depth of $\sim 1,000$ m (Methods). This modelling framework synthesises current knowledge on the biology, ecology and population dynamics of the key life stages of tuna species (from larvae to mature fish) in their oceanic ecosystem and has been validated against a large set of observations (Methods and Supplementary Note 7). We assume that the relationships and mechanisms inherent in SEAPODYM will remain valid over the next few decades.

We modelled the responses of tuna biomass to the Intergovernmental Panel on Climate Change (IPCC) representative concentration pathway (RCP) 8.5, RCP 4.5 and RCP 2.6 emissions scenarios for 2050 in the EEZs of Pacific SIDS, focusing on the ten tuna-dependent SIDS (Fig. 1), and in high-seas areas 


\section{Box 1| The PNA VDS}

Pacific SIDS that are the PNA (Federated States of Micronesia, Kiribati, Marshall Islands, Nauru, Palau, Papua New Guinea, Solomon Islands and Tuvalu) have developed a system for jointly managing the purse-seine fishery targeting skipjack tuna within their combined EEZs. It is called the Vessel Day Scheme (VDS ${ }^{69}$ (Supplementary Note 4). Tokelau also participates in the VDS under a memorandum of understanding with PNA.

The 'cap and trade' VDS sets the total annual purse-seine fishing effort within the combined EEZs of PNA members at $\sim 45,000$ fishing days and allocates these days to members on the basis of individual EEZ areas and their past 8-10 years of fishing effort history. The VDS provides a trading mechanism among PNA members ${ }^{70,71}$, allowing them to respond to the profound effects of ENSO on the warm pool and the prime fishing grounds for skipjack tuna ${ }^{5,6}$. During La Niña events, the best catches of skipjack tuna are made in the west of the region (see top panel in the following diagram), whereas during El Niño events fishing is most efficient up to $4,000 \mathrm{~km}$ to the east (see bottom panel). During La Niña events, the VDS enables countries in the west to buy fishing days from members in the east, enabling fleets to keep fishing in the west. The reverse occurs during El Niño events. Therefore, regardless of where the tuna are caught, all PNA members receive access fees every year. In this way, the VDS evens out the previously high interannual variability in access fees received by PNA members and helps stabilize government revenue for tuna-dependent economies.
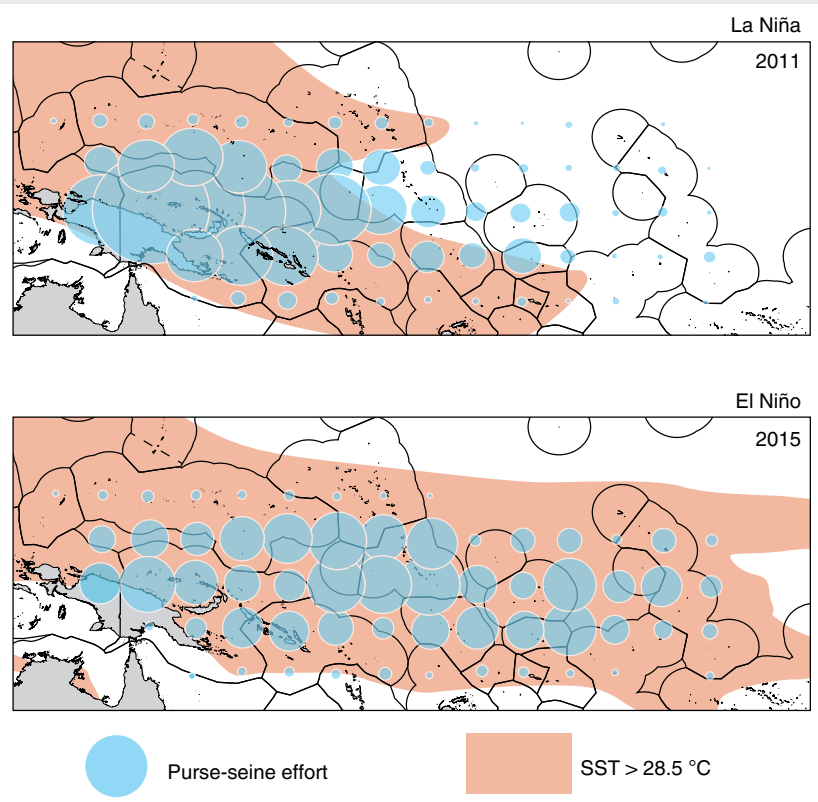

The various provisions of the VDS-transferability of fishing days among PNA members, 'pooling' of days by groups of members, and 'roaming' of vessels from PNA member countries among their collective $\mathrm{EEZs}^{70}$-also provide non-confrontational adaptations to the progressive redistribution of skipjack tuna within the combined EEZs of PNA members due to ocean warming $^{70,71}$ (Supplementary Note 4). However, the VDS does not encompass adaptations for the redistribution of tuna from the EEZs of PNA members to high-seas areas.

(Supplementary Fig. 1) (Methods). Projections for RCP 4.5 and RCP 2.6 were estimated on the basis of examining changes in the RCP 8.5 simulation at the times when $\mathrm{CO}_{2}$ concentrations reach those equivalent to RCP 4.5 and RCP 2.6 in 2050 (Methods). Estimating the effects of the lower-emissions scenarios in this way was necessary because appropriate ocean forcings, with bias-corrected physical and biogeochemical variables, do not yet exist for RCP 4.5 and RCP 2.6.

Our modelling of climate-driven redistribution of tuna under RCP 8.5 by 2050 (Fig. 2 and Supplementary Fig. 2) indicates that total biomass of the three species (tuna biomass) in the combined jurisdictions of the 10 Pacific SIDS would decrease by an average of $13 \%$ (range $=-5 \%$ to $-20 \%$ ) (Fig. 3a) and by up to $~ 30 \%$ in 10 of the 12 individual EEZ areas (noting that Kiribati has three separate EEZ areas) (Supplementary Table 5). Conversely, tuna biomass is projected to increase by an average of $23 \%$ (range $=13 \%$ to $32 \%$ ) in the central EPO (EPO-C, Fig. 3a), the high-seas area where most tuna are caught (Supplementary Table 4). Tuna biomass is also projected to increase by an average of up to $20 \%$ in nine other high-seas areas (Supplementary Table 6) and by an average of $12 \%$ in all high-seas areas combined (Supplementary Fig. 5). These projected changes in tuna biomass by 2050 generally reflect the contrasting responses of sea surface temperature (SST), primary production and the prey organisms of tuna to RCP 8.5 in the WCPO and EPO (Supplementary Figs. 3 and 4).

The projected effects of the more moderate, surrogate RCP 4.5 emissions scenario (RCP 4.5) on redistribution of tuna biomass (Fig. 2) are far less pronounced (Fig. 3a). Under this scenario, total biomass of tuna in the combined EEZs of the ten Pacific SIDS decreases by an average of only $1 \%$ (range $=-9 \%$ to $+8 \%$ ), and decreases occur on average in only three EEZ areas (Supplementary Table 7). By contrast, the projected effects of RCP 4.5 on tuna biomass in high-seas areas are similar to those for RCP 8.5; that is, there is an average increase of $18 \%$ (range $=+9 \%$ to $+32 \%$ ) in EPO-C (Fig. 3a), an average increase of up to $19 \%$ in 11 of the other high-seas areas (Supplementary Table 8) and an average increase of $11 \%$ in all high-seas areas combined (Supplementary Fig. 5). A possible explanation for the substantial increases in tuna biomass in high-seas areas under RCP 4.5 by 2050 is the stronger response to increased GHG emissions by the food web supporting tuna in the EPO than in the WCPO (Supplementary Fig. 4).

On average, the biomass of tuna in the combined EEZs of all other Pacific SIDS (which occur mainly in sub-equatorial waters) also increased under RCP 8.5 and RCP 4.5 (Supplementary Tables 9 and 10). However, this increase was less than $20 \%$ of the increase in EPO-C (Supplementary Fig. 5), indicating that most redistribution of tuna biomass within the Pacific Ocean is projected to occur in equatorial areas.

Results for the strong mitigation RCP 2.6 simulations are not presented because the uncertainty associated with using RCP 8.5 forcings to estimate RCP 2.6 is too high to have reasonable confidence in the results (Methods).

\section{Implications for tuna catches}

The projected changes in tuna biomass due to increased GHG emissions are expected to affect purse-seine catches of tuna from the EEZs and high-seas areas (Methods). By 2050 under RCP 8.5, the total purse-seine catch from the combined EEZs of the ten tuna-dependent Pacific SIDS is estimated to decrease by an average of $20 \%$ (range $=-30 \%$ to $-10 \%$ ), that is, 284,000 tonnes (range $=-428,000$ to $-143,000$ tonnes); it is estimated to increase by an average of $27 \%$ (range $=+15 \%$ to $+37 \%$ ), that is, 125,000 tonnes (range $=+69,000$ to $+169,000$ tonnes), in EPO-C (Table 1, Fig. 3 b and Supplementary Tables 11 and 12).

The projected changes in purse-seine catch by 2050 under RCP 4.5 also follow the patterns in tuna biomass, decreasing by an average of $3 \%$ (range $=-12 \%$ to $+9 \%$ ), that is, 47,000 tonnes (range $=-165,000$ to $+124,000$ tonnes), in the combined EEZs of the ten Pacific SIDS and increasing in EPO-C by an average of $18 \%$ 

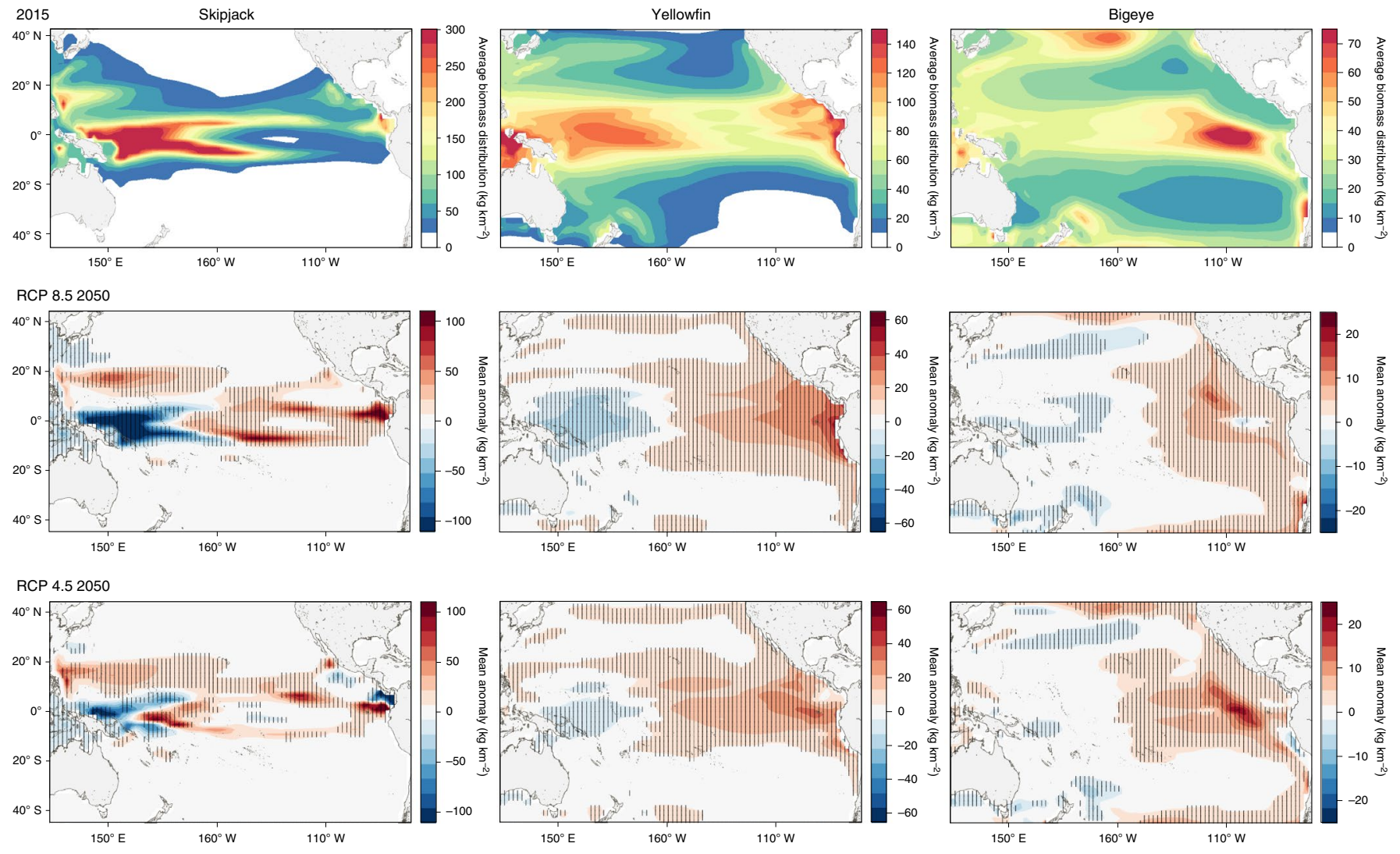

Fig. 2 | Projected effects of climate change on the distributions of the three tuna species caught by purse-seine fishing in the Pacific Ocean. Average biomass distributions ( $\mathrm{kg} \mathrm{km}^{-2}$ ) of skipjack, yellowfin and bigeye tuna in the Pacific Ocean basin for 2015 (2011-2020) (top row) and mean anomalies $\left(\mathrm{kg} \mathrm{km}^{-2}\right)$ from the average 2015 biomass distribution of each tuna species projected to occur by 2050 (2044-2053) under two emissions scenarios, RCP 8.5 (middle row) and RCP 4.5 (bottom row). Shading indicates areas where projections from all four ESMs (Methods) agree in the sign of change, excluding near-zero changes (white zones).

(range $=+7 \%$ to $+34 \%$ ), that is, 84,000 tonnes (range $=+32,000$ to $+154,000$ tonnes) (Table 1 , Fig. $3 \mathrm{~b}$ and Supplementary Tables 13 and 14).

\section{Effects on tuna-dependent economies}

The estimated changes in purse-seine catch under RCP 8.5 could reduce total annual fishing access fees earned by the ten Pacific SIDS by an average of US $\$ 90$ million (range $=-U S \$ 40$ million to -US $\$ 140$ million) per year compared with the average annual revenue received between 2015 and 2018 (Table 2 and Supplementary Table 15). Losses in access fees are estimated to occur in all ten Pacific SIDS under RCP 8.5, and reduce total government revenue by up to $13 \%$ (range $=-8 \%$ to $-17 \%$ ) for individual Pacific SIDS, by 2050 (Table 2 and Supplementary Table 15).

Under RCP 4.5, the average change in access fees for all ten Pacific SIDS represents a loss of US $\$ 12$ million (range $=-U S \$ 54$ million to +US\$48 million) per year (Table 2 and Supplementary Table 16). Due to the more-limited loss of access fees under RCP 4.5, total government revenue in 2050 is estimated to decrease by an average of $1 \%$ or less in only three of the ten Pacific SIDS (Table 2 and Supplementary Table 16).

The estimates of reduced access fees, and flow-on losses in government revenue, due to climate-driven redistribution of tuna include a number of assumptions (Methods) but, overall, are probably conservative because they do not account for the control that the ten Pacific SIDS exert in the marketplace. At present, these Pacific SIDS command high access fees because $~ 90 \%$ of the catch from the purse-seine fishing grounds within the Pacific Island region of the WCPO comes from their combined EEZs (Supplementary Note 1). However, if there is substantial movement of fish from the EEZs to high-seas areas, the ten Pacific SIDS would be unlikely to obtain the same daily rates for fees. Any such effects are also likely to occur to some extent under RCP 4.5, which is projected to reduce catches in the combined EEZs of the ten Pacific SIDS by $~ 50,000$ tonnes and increase catches in high-seas areas by more than 100,000 tonnes (Table 1).

Even at conservative levels, the estimated losses in fishing access fees are expected to have substantial implications for economic development. They would coincide with the need for increased financial resources and flexibility to adapt to climate change, including sustained government facilitation of community-based initiatives ${ }^{18}$. The projected reductions in tuna biomass and catch are also expected to affect the ability of many of the ten Pacific SIDS to harmonize the employment, value-adding and food security goals of the Roadmap ${ }^{3}$ and achieve sustainable development ${ }^{19,20}$. With a lower biomass of tuna within their EEZs, several of the ten Pacific SIDS may need to use a greater proportion of their tuna resources for local consumption $^{2}$, further limiting the scope for earning access fees and potentially reducing the supply of tuna that supports employment in national canneries.

\section{Implications for fisheries management}

The projected climate-driven redistribution of tuna biomass and purse-seine catches also has potential implications for sustainable management of the world's largest tuna fishery. In a scenario where 


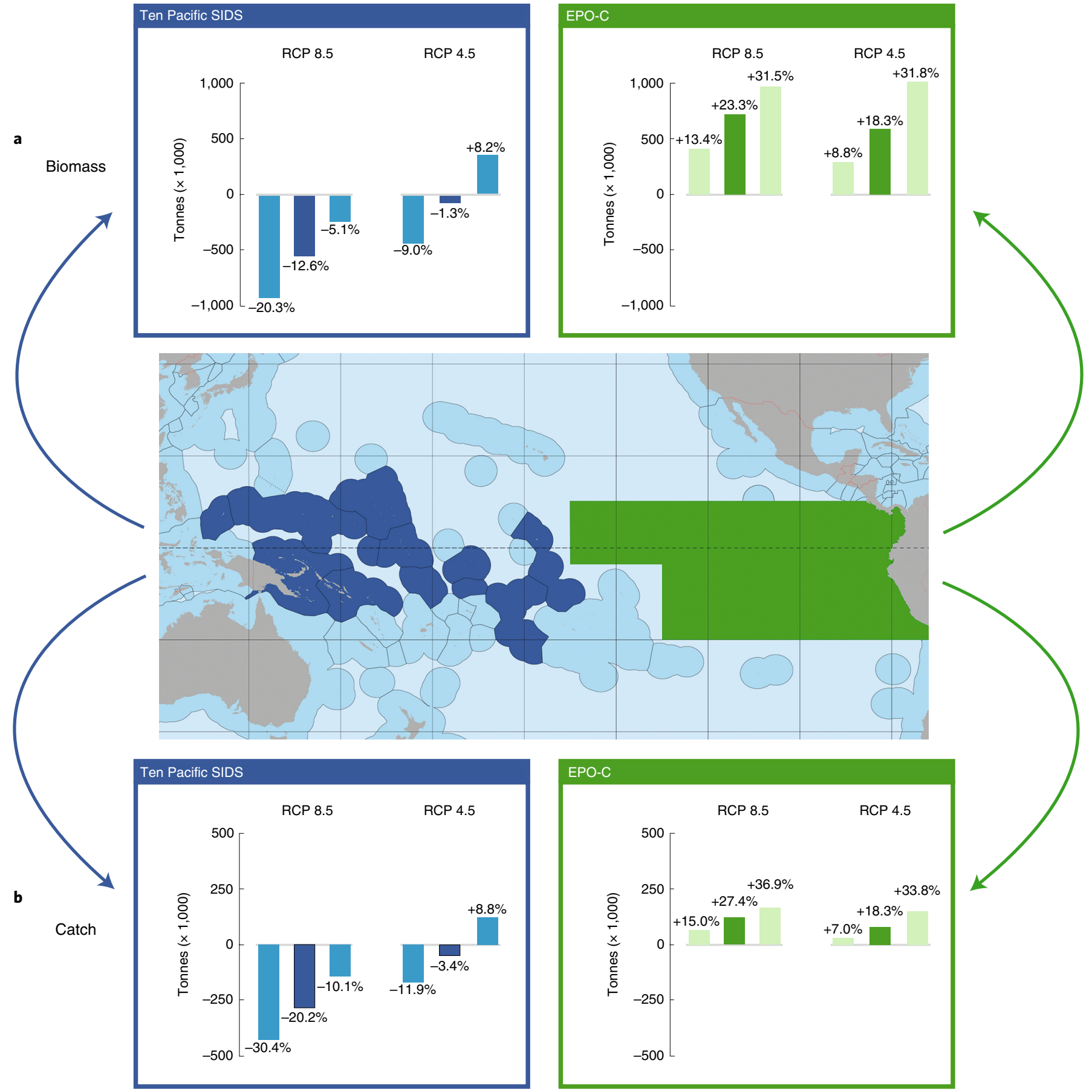

Fig. 3 | Redistribution of tuna biomass and purse-seine catch from the combined EEZs of the ten tuna-dependent Pacific SIDS to the central eastern

Pacific Ocean. a, Projected changes in total biomass of skipjack, yellowfin and bigeye tuna in the combined EEZs of the ten Pacific SIDS and EPO-C under the RCP 8.5 and RCP 4.5 emissions scenarios in 2050 relative to the average biomass from these areas in 2009-2018. b, Projected changes in total purse-seine catch in the EEZs of the ten Pacific SIDS and EPO-C under the RCP 8.5 and RCP 4.5 emissions scenarios in 2050 relative to the average catch from these areas in 2009-2018. The dark column in each histogram represents the average change from the four ESMs. The columns on either side of the average represent the maximum and minimum changes projected by the range of ESMs. See Supplementary Tables 5-8 for further details of changes in biomass and Supplementary Tables 11-14 for details of changes in purse-seine catch. Projected changes in biomass and catch for all high-seas areas combined are presented in Supplementary Fig. 5.

a lower proportion of tuna resources is under the jurisdiction of the PNA VDS (Box 1), the sustainability of tuna catches could be at greater risk because the monitoring, control and surveillance required to combat illegal, unreported and unregulated fishing, and impose penalties for non-compliance, are more difficult in high-seas areas ${ }^{21}$. This is because responsibility for compliance with fishing regulations on the high seas rests with the states that 'flag' fishing vessels (often resulting in self-regulation), whereas compliance within EEZs is under the purview of coastal states. With continued GHG emissions, the onus will be on WCPFC to implement tighter controls on fishing for tropical tuna species by all vessels operating in high-seas areas of the WCPO. 
Table 1| Average projected changes in purse-seine catch from the EEZs of tuna-dependent Pacific SIDS and high-seas areas

\begin{tabular}{|c|c|c|c|c|c|c|c|}
\hline \multirow[t]{2}{*}{ Area } & \multirow[t]{2}{*}{ Average catch (t) } & \multicolumn{3}{|c|}{ RCP 8.52050} & \multicolumn{3}{|c|}{ RCP 4.52050} \\
\hline & & Catch (t) & Change (t) & Change (\%) & Catch (t) & Change (t) & Change (\%) \\
\hline \multicolumn{8}{|l|}{ EEZs of Pacific SIDS } \\
\hline FSM & 178,587 & 155,407 & $-23,180$ & -13.0 & 173,773 & $-4,815$ & -2.7 \\
\hline Kiribati & 396,048 & 363,520 & $-32,528$ & -8.2 & 423,251 & $+27,202$ & +6.9 \\
\hline Gilbert Islands ${ }^{a}$ & $(260,073)$ & $(225,177)$ & $(-34,896)$ & $(-13.4)$ & $(278,023)$ & $(+17,950)$ & $(+6.9)$ \\
\hline Line Islands ${ }^{a}$ & $(41,279)$ & $(46,203)$ & $(+4,924)$ & $(+11.9)$ & $(44,096)$ & $(+2,817)$ & $(+6.8)$ \\
\hline Marshall Islands & 37,003 & 36,728 & -275 & -0.7 & 37,778 & +775 & +2.1 \\
\hline Nauru & 110,794 & 86,886 & $-23,908$ & -21.6 & 117,059 & $+6,266$ & +5.7 \\
\hline Palau & 2,655 & 2,646 & -9 & -0.3 & 2,738 & +82 & +3.1 \\
\hline Papua New Guinea & 461,032 & 308,404 & $-152,628$ & -33.1 & 389,654 & $-71,378$ & -15.5 \\
\hline Total EEZs & $1,408,548$ & $1,124,577$ & $-283,971$ & -20.2 & $1,361,257$ & $-47,291$ & -3.4 \\
\hline \multicolumn{8}{|l|}{ High-seas areas } \\
\hline 11 & 15,330 & 11,396 & $-3,934$ & -25.7 & 13,541 & $-1,790$ & -11.7 \\
\hline 12 & 23,083 & 16,413 & $-6,670$ & -28.9 & 20,738 & $-2,345$ & -10.2 \\
\hline 13 & 47 & 60 & +13 & +27.8 & 61 & +14 & +29.8 \\
\hline 14 & 21,443 & 21,773 & +330 & +1.5 & 22,727 & $+1,284$ & +6.0 \\
\hline 15 & 23,231 & 28,021 & $+4,790$ & +20.6 & 26,194 & $+2,963$ & +12.8 \\
\hline 16 & 16,211 & 16,868 & +657 & +4.1 & 17,800 & $+1,589$ & +9.8 \\
\hline 17 & 16.7 & 18 & +1.3 & +9.0 & 17 & +0.2 & +1.3 \\
\hline EPO-S & 3,293 & 4,339 & $+1,046$ & +31.8 & 3,747 & +454 & +13.8 \\
\hline Total high seas & 711,939 & 849,755 & $+137,816$ & +19.4 & 815,856 & $+103,917$ & +14.6 \\
\hline
\end{tabular}

Ten-year (2009-2018) average purse-seine tuna catches in tonnes ( $t$ ) from the EEZs of ten Pacific SIDS and high-seas areas together with average projected changes to these catches by 2050 in tonnes

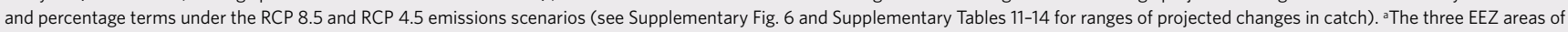
Kiribati, which have been integrated to produce the total for Kiribati. FSM, Federated States of Micronesia; see Supplementary Fig. 1 for locations and definitions of all high-seas areas.

Sustainable management of tropical Pacific tuna resources will also be challenged by the substantial projected increases in average tuna biomass in the EPO-C high-seas area, particularly under RCP 8.5 (Fig. $3 a$ and Table 1). This will necessitate closer collaboration between WCPFC and the regional fisheries management organization for the EPO, the Inter-American Tropical Tuna Commission (IATTC). The shared governance arrangements between WCPFC and IATTC that are already in place for the overlap in their convention areas (Supplementary Fig. 1) will need to be expanded and strengthened to avoid the problems that have accompanied management of climate-driven shifts in fish distribution in other jurisdictions ${ }^{22,23}$ and to address the economic impacts that reductions in access fees would have on tuna-dependent Pacific SIDS.

Increased tuna biomass in high-seas areas will also need to be considered during the application of the emerging instrument for conservation and sustainable use of marine biological diversity in areas beyond national jurisdiction (BBNJ Agreement) under the
United Nations Convention on the Law of the Sea ${ }^{24}$ (Supplementary Note 8). Although the BBNJ Agreement has been designed to avoid undermining existing governance regimes in high-seas areas ${ }^{25,26}$, questions remain regarding interactions between fisheries management and components of the agreement related to area-based management, transfer of technology and capacity building ${ }^{27,28}$. Accordingly, WCPFC and IATTC will need to develop transparent systems for information exchange and cooperation with the BBNJ institutional framework and manage any new impacts between fisheries and high-seas biodiversity caused by climate change.

\section{Pathways to sustaining tuna-dependent economies}

Development of responsible systems for the sustainable management of tropical tuna resources and maintenance of high-seas biodiversity are not the only challenges as the Pacific Ocean is transformed by GHG emissions. The projected declines in government revenue for tuna-dependent Pacific Island economies due to tuna 
Table 2 | Projected changes in tuna-fishing access fees and government revenue for the ten tuna-dependent Pacific SIDS

Pacific SIDS

Average 2015-2018

Change by 2050 (RCP 8.5)

Change by 2050 (RCP 4.5)

\begin{tabular}{|c|c|c|c|c|c|c|c|c|}
\hline $\begin{array}{l}\text { Government } \\
\text { revenue (million } \\
\text { US\$) }\end{array}$ & $\begin{array}{l}\text { Access fees } \\
\text { (million } \\
\text { US\$) }\end{array}$ & $\begin{array}{l}\text { Access fees } \\
\text { as } \% \text { of } \\
\text { government } \\
\text { revenue }\end{array}$ & $\begin{array}{l}\text { Purse-seine } \\
\text { tuna catch } \\
(\%)^{a}\end{array}$ & $\begin{array}{l}\text { Access } \\
\text { fees } \\
\text { (million } \\
\text { US\$) }\end{array}$ & $\begin{array}{l}\text { Government } \\
\text { revenue (\%) }\end{array}$ & $\begin{array}{l}\text { Purse-seine } \\
\text { tuna catch } \\
(\%)^{a}\end{array}$ & $\begin{array}{l}\text { Access fees } \\
\text { (million } \\
\text { US\$) }\end{array}$ & $\begin{array}{l}\text { Government } \\
\text { revenue (\%) }\end{array}$ \\
\hline 126.1 & 13.5 & 10.6 & -4.0 & -0.5 & -0.4 & +8.9 & +1.2 & +1.0 \\
\hline 150.6 & 68.4 & 47.6 & -13.0 & -8.9 & -5.9 & -2.7 & -1.8 & -1.2 \\
\hline 181.7 & 128.3 & 70.6 & -8.2 & -10.5 & -5.8 & +6.9 & +8.9 & +4.9 \\
\hline 66.1 & 31.0 & 47.8 & -0.7 & -0.2 & -0.3 & +2.1 & +0.7 & +1.0 \\
\hline 98.6 & 29.5 & 31.1 & -21.6 & -6.4 & -6.5 & +5.7 & +1.7 & +1.7 \\
\hline 75.2 & 7.1 & 9.4 & -0.3 & -0.02 & -0.03 & +3.1 & +0.2 & +0.3 \\
\hline $3,360.8$ & 134.3 & 4.0 & -33.1 & -44.4 & -1.3 & -15.5 & -20.8 & -0.6 \\
\hline 429.0 & 41.3 & 9.6 & -26.1 & -10.8 & -2.5 & -8.7 & -3.6 & -0.8 \\
\hline 16.0 & 13.4 & 84.2 & -16.1 & -2.1 & -13.4 & +5.7 & +0.8 & +4.8 \\
\hline \multirow[t]{2}{*}{47.4} & 25.6 & 53.9 & -23.4 & -6.0 & -12.6 & +3.4 & +0.9 & +1.9 \\
\hline & 492.4 & & & -89.9 & & & -12.0 & \\
\hline
\end{tabular}

Cook Islands

FSM

Kiribati

Marshall Islands

Nauru

Palau

PNG

Solomon Islands

Tokelau

Tuvalu

492.4

Average government revenue (excluding grants), tuna-fishing access fees and the percentage of government revenue derived from access fees for ten tuna-dependent Pacific SIDS between 2015 and 2018 together with estimated changes in purse-seine tuna catch, access fees and government revenue, by 2050 under the RCP 8.5 and RCP 4.5 emissions scenarios. See Supplementary Tables 15 and 16 for ranges of estimated percentage changes in access fees and government revenue by 2050 , and details of the calculations summarized here. PNG, Papua New Guinea. aProjected change in average total purse-seine catch due to climate-driven redistribution of total tuna biomass (Supplementary Tables 17 and 18).

redistribution also highlight the need to identify pathways to sustain these economies and secure climate justice ${ }^{29}$ for these Pacific SIDS (Supplementary Note 9).

The United Nations Convention on the Law of the Sea is silent on climate change. However, the most important pathway to sustaining Pacific Island economies is common to all climate justice action-reduction of GHG emissions to limit global temperature rise to $1.5^{\circ} \mathrm{C}$ by the end of the century ${ }^{30}$. Although the effects of RCP 2.6 (which limits warming to $\sim 2^{\circ} \mathrm{C}$ by 2100 , approximating the aspirations of the Paris Agreement) could not be assessed effectively during this study, the marked difference between projected tuna catches across the tropical Pacific Ocean under RCP 8.5 and RCP 4.5 (Table 1 and Fig. 3) indicates that further reductions to GHG emissions to achieve the goals of the Paris Agreement should substantially reduce the potential impacts of climate change for tuna-dependent economies. This conclusion is supported by modelling for other fisheries ${ }^{31}$.

However, another pathway based on a regional approach is also essential for sustaining the economies of tuna-dependent Pacific SIDS in case there is inadequate progress in attaining the goals of the Paris Agreement. This pathway involves negotiation, through the Convention on the Conservation and Management of Highly Migratory Fish Stocks in the Western and Central Pacific Ocean (WCPF Convention) ${ }^{32}$, to enable Pacific SIDS to retain the socioeconomic benefits they now receive from tuna, regardless of climate-driven redistribution of the fish (Supplementary Note 10). The WCPF Convention is the appropriate vehicle for these negotiations because it is based on the important principles of international cooperation and long-term sustainability established under the 1995 United Nations Fish Stocks Agreement ${ }^{33}$. The conservation and management measures within the WCPFC provide the framework for negotiations to ensure that catches are consistent with the objective of long-term conservation of tuna resources, conservation and management measures consider the special requirements of developing States and do not place a disproportionate burden of conservation action on such States, and the respective dependence on fish resources by members of the WCPF Convention, including Pacific SIDS, are taken into account. Such negotiations should recognize the injustice of climate-driven tuna redistribution for Pacific SIDS, be guided by WCPFC Resolution 2019-01 on Climate Change (Supplementary Note 6) and consider conferring more responsibility for management of tuna in high-seas areas of the WCPO to Pacific SIDS.

On the basis of its existing conservation and management measures, WCPFC agreed in 2017 to begin a process for adopting hard limits for the high-seas purse-seine fishery for tropical tuna and allocating access rights ${ }^{34}$ (Supplementary Note 11). This process will be compatible with the existing limits that apply to EEZs and provide a mechanism for WCPFC to ensure that the benefits of rights that presently accrue to Pacific SIDS are locked in for the long term ${ }^{35}$. Allocation of long-term rights would substantially mitigate the projected effects of tuna biomass declines within the EEZs of the ten tuna-dependent Pacific SIDS and maintain the revenues they derive from industrial fishing. A member of WCPFC (South Korea) has already suggested exploring the possibility of making PNA vessel days (Box 1) transferable to high-seas areas, under present-day conditions when fish are more abundant there, in ways that do not jeopardize the sovereign rights or aspirations of PNA members ${ }^{36}$. Such an arrangement could lay the foundation for enabling distant-water fishing fleets to continue paying revenue to PNA members for access to their EEZs but use the vessel days to fish on the high seas when catch rates are better there. It is a prime example of a possible equitable solution within the 'negotiation' pathway.

In the event that negotiations within the WCPFC are unsuccessful, Pacific SIDS could use a conciliation commission, based on the dispute settlement mechanism under the WCPF Convention and international law, to identify a lasting solution that incorporates an appropriate level of flexibility and stability. Other possible mechanisms available to the tuna-dependent Pacific SIDS include the United Nations Framework Convention on Climate Change Warsaw International Mechanism for Loss and Damage (Supplementary Note 12) and the Climate Security Mechanism of the United Nations (Supplementary Note 13).

Although the rationale for the negotiations outlined here is based on the projected redistribution of tuna, we recognize that there are also systemic and procedural issues associated with the prevailing 
circumstances $^{37-39}$. These issues should also be examined to identify the full dimensions of justice and equity for tuna-dependent Pacific SIDS.

\section{Discussion}

This analysis demonstrates that sustainable development of tuna-dependent economies in the Pacific Island region is likely to be at substantial risk from continued high GHG emissions. Although considerable uncertainty remains, our modelling provides sufficient information to indicate that it is not a question of 'if' tuna biomass will shift from the combined EEZs of the ten Pacific SIDS but 'when, how quickly and to what extent'. It is important that this risk be recognized by the United Nations Framework Convention on Climate Change and included in the rationale for limiting global warming in line with the Paris Agreement.

The process to identify a mechanism to eliminate or substantially reduce this risk for tuna-dependent Pacific SIDS, based on the principles of cooperation and long-term sustainability through the WCPF Convention, should also begin immediately. Ultimately, the necessary international negotiations will be facilitated by reducing uncertainty in the timing and extent of tuna redistribution and the associated impacts on catch, access fees and government revenue.

Reducing the remaining uncertainty in redistribution of tuna biomass will depend on improving tuna modelling to increase the spatial resolution (for example, up to $0.5^{\circ}$ ), incorporating ocean forcings for all emissions scenarios considered in the Coupled Model Intercomparison Project Phase 6 (CMIP6), integrating additional and enhanced biogeochemical models into the simulation ensemble for the impacts of ocean warming and acidification on the food webs that support tuna, and assessing the effects of the Interdecadal Pacific Oscillation ${ }^{40}$ on the onset of accelerated ocean warming. Preliminary genetic research, showing that some tropical tuna species are composed of multiple, self-replenishing populations ('stocks') ${ }^{41-44}$, indicates that efforts to reduce uncertainty in redistribution of tuna biomass will also be strengthened by identifying the stock structure of each species. This would enable the response of each stock to climate change to be modelled separately and then aggregated to produce a more accurate understanding of tuna redistribution from EEZs to high-seas areas.

Once improved estimates of biomass redistribution are available, and policy alternatives have been developed to limit the vulnerability of Pacific SIDS, bio-economic modelling will be needed to help reduce uncertainty in future purse-seine catches and the associated contributions to tuna-dependent economies. Such modelling should explore the effects of different fleet-dynamics and market-force scenarios on catch rates and government revenue derived from access fees. It should also examine the extent to which various proposed policies and regional fisheries management arrangements empower the ten Pacific SIDS to maintain control over their historical levels of purse-seine catch.

These investments will not only enable tuna-dependent Pacific SIDS to negotiate more effectively for the international agreements and management actions required to sustain their economies, they will also provide WCPFC and IATTC with the information needed to identify shared stocks, improve stock assessments and harmonize their conservation and management measures-information that is essential for minimizing the impact of climate change on the sustainability of tuna resources ${ }^{45}$.

\section{Methods}

Ocean forcings. The Nucleus for European Modelling of the Ocean (NEMO) ocean framework ${ }^{46}$, which includes an online coupling with the biogeochemical component PISCES in a $2^{\circ}$ latitude $\times 2^{\circ}$ longitude configuration ${ }^{47,48}$, was used to simulate the historical oceanic environment (hindcast simulation). This historical simulation was forced by the Drakkar Forcing Sets 5.2 (DFS5.2) ${ }^{49}$ on the basis of a corrected set of the European Centre for Medium-Range Weather Forecasts (ECMWF) Reanalysis - Interim (ERA-Interim) over the period 1979-2011.
Salinity, temperature and biogeochemical tracer concentrations (nitrate, phosphate, iron, silicate, alkalinity, dissolved oxygen and dissolved organic and inorganic carbon) were initialized from the World Ocean Atlas climatology (WOA09) ${ }^{50}$ and previous model climatology for iron and dissolved organic carbon ${ }^{51}$. To minimize any substantial numerical drift in the simulations related to a non-equilibrated initial state, we applied a spin-up of the ocean model and biogeochemical model for 66 years, cycling twice over the DFS5.2 forcing sets ${ }^{48}$.

Overall, the model simulates basin-scale, historical SST and salinity distribution, together with seasonal and interannual (ENSO) variability with good fidelity ${ }^{52}$. Classical biases are associated with the coarse $\left(2^{\circ}\right)$ resolution, for example, the latitudinal position of the Kuroshio Current. In the tropical Pacific, there is a cold bias of $-1^{\circ} \mathrm{C}$ in the central equatorial zone (between $170^{\circ} \mathrm{W}$ and $100^{\circ} \mathrm{W}$ ) and a warm bias of $+1^{\circ} \mathrm{C}$ in the eastern part of the basin (east of $90^{\circ} \mathrm{W}$ ). Despite some local discrepancy between simulation outputs and satellite-derived chlorophyll concentration around islands and near the American coasts, simulated mean chlorophyll in the equatorial Pacific Ocean is close to observed values ${ }^{51,52}$.

For future ocean projections, we first selected several ESMs from the CMIP5 intercomparison project ${ }^{53}$ on the basis of the ability of the models to produce accurate ENSO variability in the Pacific ${ }^{54}$. The four ESMs selected were IPSL-CM5A ${ }^{55}$, MIROC $^{56}$, GFDL-ESM2 ${ }^{57}$ and MPI-MR ${ }^{58}$. We then extracted atmospheric fields from these models for the period 2011-2100 under RCP 8.5 to simulate 'business-as-usual' climate anomalies to build forcing sets for the NEMOPISCES ocean model.

All ESMs display large biases in their representation of Pacific climate, including the important South Pacific Convergence Zone ${ }^{59,60}$. These atmospheric biases propagated uncertainties associated with future atmospheres into the coupled, dynamical-biogeochemical oceanic framework. For example, they result in prominent distortions in the extension and position of the warm pool ${ }^{61}$ and can be expected to affect modelling of the open ocean ecosystem up to the higher trophic levels ${ }^{12}$

To mitigate the mean state model biases in the selected ESMs, we used a 'pseudo-warming' anomaly approach to force the ocean model. To do this, we extracted monthly anomalies (relative to 2010) of surface atmospheric temperature, zonal and meridional wind speeds, radiative heat fluxes, relative humidity and precipitation from the ESM models over the 2010-2100 period and applied a 31-year-wide Hanning filter to remove variability on timescales less than 15 years.

Each ESM-filtered timeseries was superimposed onto the repeating 30-year historical forcing (that is, repeated three times to span the twenty-first century) to provide the forcing for the NEMO-PISCES projections. This procedure enabled us to retain a realistic climatology and high-frequency variability from observations subject to long-term trends due to climate change based on the ESMs (Supplementary Fig. 7).

For consistency, the control simulation of NEMO-PISCES was forced using the same three, repeated, 30-year historical periods to correct any long-term drift generated internally without climate change forcing.

It is important to note that use of all ESM acronyms (for example, IPSL) in the following text refers to NEMO-PISCES or SEAPODYM simulations derived from the ESM anomaly forcing, and not to the ESM models themselves.

The four NEMO-PISCES simulations of future ocean conditions produced contrasting results in terms of dynamics and biogeochemistry (Supplementary Fig. 8). In particular, there was strong warming in the IPSL and MIROC simulations and weaker warming for GFDL and especially MPI. Spatial patterns in ocean warming produced by the NEMO-PISCES simulations differed mostly in intensity rather than spatial structure.

Using NEMO-PISCES outputs to produce SEAPODYM forcings. The outputs of NEMO-PISCES were used to provide environmental forcing variables for SEAPODYM, the model used to project the responses of the key life stages of skipjack, yellowfin and bigeye tuna to climate change (Supplementary Note 7). The following physical and biochemical forcing variables were used in SEAPODYM applications: three-dimensional (3D) temperature, dissolved oxygen $\left(\mathrm{O}_{2}\right)$ concentration, zonal/meridional currents and primary production, and $2 \mathrm{D}$ euphotic depth. Before running SEAPODYM, these forcing variables were interpolated to a regular $2^{\circ}$ Arakawa A grid and placed in the centre of the grid cells. Primary production was then vertically integrated throughout the water column, whereas the other 3D variables were integrated within three pelagic layers, defined according to the euphotic depth to provide the mean 2D fields for each variable per layer. Selected environmental variables from the historical ocean reanalysis and from four climate-driven ocean outputs are shown in Supplementary Fig. 3.

These integrated variables were then used to force the SEAPODYM-LMTL (lower and mid-trophic level) sub-model. SEAPODYM-LMTL relies on primary production, temperature and ocean currents to simulate the biomass of six functional groups of micronekton-mid-trophic-level prey organisms of tunas (Supplementary Fig. 4)-residing or migrating through three pelagic layers within the upper $1,000 \mathrm{~m}$ of the water column (the epipelagic layer and the upper and lower mesopelagic layers), with depths linked to the depth of euphotic layer $Z$ as $1.5 \mathrm{Z}, 4.5 \mathrm{Z}$ and $10 \mathrm{Z}$ (with $10 \mathrm{Z}$ limited to $1,000 \mathrm{~m}$ ). The definition of these pelagic layers is derived from the diurnal vertical distributions of micronekton species ${ }^{62}$. 
Optimal parameterization of SEAPODYM during historical period. The parameterization of SEAPODYM for each tuna species is highly sensitive to ocean forcing; that is, in its average state it is free from systematic biases, and it represents interannual variability and ENSO correctly. This sensitivity enables the model to reproduce observed variability within large, geo-referenced datasets of tuna catches and length distributions reflecting changes in fish abundance ${ }^{12}$. The environmental forcings in this study were obtained from the historical NEMO-PISCES reference simulations using a realistic atmospheric reanalysis based on a consistent set of atmospheric observations. Historical fishing datasets used to achieve model optimal parameterizations were compiled from the combination of data provided by the Pacific Community for the WCPO and by IATTC for the EPO. The model spatial resolution was $2^{\circ} \times 2^{\circ}$, and the resolution for time and age dimensions was one month. The skipjack tuna reference model was obtained by integrating all available geo-referenced data-catch, length-frequency of catch and tagging release-recapture data-into a likelihood function and obtaining the solution using the maximum likelihood estimation (MLE) approach (Supplementary Note 7). The initial habitat and movement parameters for bigeye and yellowfin tuna were also estimated by integrating tagging data into the model; however, the final parameterizations of the reference models for these two species were based mainly on fisheries data. The methodology and optimal reference solutions obtained for skipjack, yellowfin and bigeye tuna, and model validations with statistical metrics, are described in other publications documenting the use of SEAPODYM ${ }^{13,63-65}$.

The structures of the populations of the three tuna species in December 2010 (the last time-step of the reanalysis) were used to set the initial conditions for the projections starting in 2011. A second historical simulation was run to remove the effects of fishing mortality (Supplementary Figs. 9 and 10) to establish the initial conditions for the unfished tuna populations (Supplementary Fig. 10). In these latter simulations, the stocks increase and reach an equilibrium state in a time that is defined by the lifespan of the species and the estimated stock-recruitment relationship. We assume that at the end of the 30-year reanalysis (December 2010), stocks of all three tropical tuna species are at their virgin (unfished) state and influenced by environmental variability and demographic processes only.

Projections of climate change impacts on tuna. Previous studies on the impact of climate change on tropical tuna species in the Pacific Ocean produced projections based on the full-field NEMO-PISCES output from a single ESM (IPSL) under the IPCC business-as-usual scenario ${ }^{6,10,12,66,67}$. These projections were subject to biases, resulting in poor coherence between historical and projected environmenta forcings and abrupt changes and biases when switching from a historical reanalysis to a projected time series ${ }^{12}$. To reduce this problem, we used an approach based on the four, bias-corrected, projected climates from NEMO-PISCES outputs (Supplementary Methods)

Simulations of the SEAPODYM tuna model were run with parameters from the reference MLE models for the three tuna species, with forcings from the four NEMO-PISCES and mid-trophic simulations, under the RCP 8.5 scenario to project tuna population dynamics until mid-century. We estimated the virgin biomass of each species in the decade 2011-2020 and computed the relative change in biomass by 2050 (2044-2053) as follows:

$$
\delta_{B}(2050)=\frac{1}{N} \sum_{t=2011}^{2020}\left(\frac{B(t+\Delta t)}{B(t)}-1\right)
$$

where $\Delta t$ is the time interval corresponding to 33 years and $N$ is the number of monthly time steps in the selected time period (120 months between 2011 and 2020). We chose to average over 10 years at 33-year intervals to compare two distant periods with the same atmospheric variability, thus removing the possible effects of interannual variation and allowing better detection of the climate change signal.

The relative biomass change $\delta_{B}$ (2050) was computed for the EEZs of Pacific SIDS and all high-seas areas in the WCPO and EPO (Supplementary Fig. 1).

Sensitivity analyses to explore uncertainty. We analysed the impacts of climate change on skipjack, yellowfin and bigeye tuna with an ensemble of simulations focusing on the greatest sources of uncertainty in the NEMO-PISCES variables and in SEAPODYM (Supplementary Fig. 11 and Supplementary Table 21). The methods used to explore these uncertainties, and the rationale for these analyses, are explained in the Supplementary Methods.

Modelling tuna distribution under lower-emissions scenarios. The simulations based on RCP 8.5 project a redistribution of tuna biomass by 2050 as globally averaged surface temperature rises to $2{ }^{\circ} \mathrm{C}$ above pre-industrial levels by mid-century. To evaluate possible effects of a lower GHG emission scenario on tuna redistribution, we also estimated the responses of tropical tuna species to conditions similar to RCP 4.5 and RCP 2.6 by 2050 .

In the absence of ocean forcings and SEAPODYM outputs for RCP 4.5 and RCP 2.6, we used estimates based on the RCP 8.5 simulations using a 'time-shift' approach $^{68}$. This method consists of identifying the time segment in RCP 8.5 in which a key variable (for example, $\mathrm{CO}_{2}$-equivalent $\left(\mathrm{CO}_{2} \mathrm{e}\right)$ ) matches the value expected for the selected RCP in 2050. Accordingly, we selected the periods in the
RCP 8.5 curve when total $\mathrm{CO}_{2}$ e concentrations in the atmosphere reached those projected for RCP 4.5 and RCP 2.6 in 2050 (Supplementary Fig. 12). On the basis of this method, the equivalent of RCP 4.5 in 2050 is reached in 2037 under RCP 8.5 , and the equivalent for RCP 2.6 in 2050 is reached in 2026.

An important assumption of this method is that the dynamical pattern corresponding to a given change of global temperature is independent of the rate of change. This assumption is expected to be met for key features of the tropical Pacific Ocean because the upper ocean generally responds rapidly to changes in atmospheric forcing. However, this assumption is unlikely to hold for tuna population dynamics because interannual variability of tuna biomass is driven by demographic processes (recruitment and mortality), which are in turn influenced by environmental variability. Furthermore, due to the slow nature of demographic processes, the repercussions of environmental variability on tuna population dynamics are time lagged. For example, there is a time lag of 8 months between the Southern Oscillation Index and the biomass of young skipjack tuna (aged from 3 to 9 months) $)^{17}$, and a time lag of 12 months between the Southern Oscillation Index and total biomass of skipjack tuna (Supplementary Fig. 13). When combined with the effects of stock-recruitment relationships, and different generation times between tuna species, the speed and duration of climate change processes may have a profound effect on tuna biomass. Therefore, due to the rapidly changing ocean conditions in the RCP 8.5 scenario, the population status of a tuna species in the second and third decade cannot be assumed to be equivalent to that under a scenario with lower emissions by mid-century.

To address the complications associated with the population dynamics of tuna in a changing environment, we generated synthetic RCP 4.5 and RCP 2.6 2011-2050 time series by recycling the years from RCP 8.5 simulations. Note that recycling the 'equivalent' years from RCP 8.5 simulations to imitate those projected for the RCP 4.5 and RCP 2.6 scenarios involves re-using the same years multiple times because of their lower rate of change. To avoid looping the forcings over the same year multiple times, we selected several years around the equivalent RCP 8.5 year while enlarging the temporal window with increasing differences in the rates of GHG change between the two scenarios and ensuring that the mean $\mathrm{CO}_{2} \mathrm{e}$ within this window was equal to those in the target RCP 4.5 or RCP 2.6 scenario. The inverse mapping of the RCP 8.5 curve from arrays of $\mathrm{CO}_{2} \mathrm{e}$ values to the equivalent years in the RCP 8.5 simulation (Supplementary Fig. 14) provided the selected range of RCP 8.5 years to imitate the RCP 4.5 and RCP 2.6 scenarios. The NEMO-PISCES model variables from those years were then used to compute monthly climatology for each year of the surrogate RCP 4.5 or RCP 2.6 forcing to provide smoothed time series of forcing variables over the complete time range. The temporal evolution of epipelagic ocean temperature is compared for four climate models and three RCP scenarios in Supplementary Fig. 14.

The biomass changes projected for the three tuna species in 2050 under RCP 8.5 and under the lower surrogate emissions scenarios were then computed for all Pacific Island EEZs (Supplementary Fig. 15) following equation (1) (Supplementary Methods). The biomass changes projected under the RCP 4.5 forcing are smaller in magnitude than those for RCP 8.5, demonstrating that the effect of climate change is less pronounced in the simulations under this lower-emissions scenario.

The simulations under the surrogate RCP 2.6 forcing did not follow the expected pattern and were deemed to be too unreliable for use in this study (Supplementary Methods).

Estimating changes in tuna biomass in EEZs and the high seas. For this analysis, we produced reference biomasses for skipjack, yellowfin and bigeye tuna for the period 1979-2010 from quantitative assessment studies using SEAPODYM, which estimates population dynamics, habitats, movements and fisheries parameters with an MLE approach (Supplementary Note 7). The fit between observations and predictions (for catch and catch size frequencies) was used to validate the optimal solutions of the models within and outside the time window for the model parameter estimates. The fit was analysed spatially by fishery to ensure that there were no regional biases. Once the optimal solution was achieved, a final simulation was made with the same set of parameter estimates but without considering any fishing, to obtain the unfished biomass dynamics during both the historical period and the projection for the twenty-first century. The differences in unfished biomass between the historical period (2001-2010) and projections in 2050 (mean of 2046-2050) for each species were used to compute the weighted mean change in total tuna biomass in the EEZs of the ten Pacific SIDS, the high-seas areas shown in Supplementary Fig. 1 and the EEZs of the other Pacific SIDS listed in Supplementary Table 1 for the RCP 8.5 and RCP 4.5 emission scenarios by 2050 .

Estimating changes in catch in EEZs and the high seas. To evaluate the impacts of climate change scenarios on purse-seine fisheries, comparisons were restricted to the EEZs of the ten tuna-dependent Pacific SIDS and the high-seas areas, particularly EPO-C (Supplementary Fig. 1).

To estimate the effects of projected changes in biomass of skipjack, yellowfin and bigeye tuna due to RCP 8.5 and RCP 4.5 on purse-seine catches in the EEZs of Pacific SIDS and in high-seas areas by 2050, in the absence of management interventions to reallocate catch entitlements to maintain historical access rights for Pacific SIDS, we assumed that there would be a direct relationship between 
projected changes in biomass and catch. Because purse-seine catches are composed of different proportions of the three tuna species, and because each species is projected to have a different response to climate change (Fig. 2), changes in purse-seine catches by 2050 were estimated using the weighted mean response of the three tuna species to RCP 8.5 and to RCP 4.5. These estimates were derived from the average relative abundance of each species in purse-seine catches in the EEZs of the ten Pacific SIDS (Supplementary Table 3) and in high-seas areas (Supplementary Table 4) and the projected percentage change in biomass of each species under each emission scenario (Supplementary Tables 17 and 18).

The weighted average percentage changes in biomass of all tuna species combined were then applied to the 10-year average (2009-2018) purse-seine catches from the EEZs of the ten Pacific SIDS and high-seas areas (Supplementary Tables 3 and 4) to estimate the changes in purse-seine catches for these jurisdictions by 2050 under RCP 8.5 and RCP 4.5. In the case of Kiribati, which has three separate EEZ areas (Fig. 1), we estimated the change in catch for each EEZ area and amalgamated the results to produce the overall estimated change in purse-seine catch for the country.

The projected percentage change in total purse-seine catch differs from the percentage change in total tuna biomass due to variation in the relative contributions of the three tuna species to total catch and to total biomass.

Estimating the effects of tuna redistribution on economies. To assess the effects of climate-driven redistribution of tuna on the economies of the 10 Pacific SIDS, we assumed that estimated changes in purse-seine catch within their EEZs due to the redistribution of tuna biomass described above would result in a proportional change in access fees earned from purse-seine fishing and associated operations.

To estimate the effects of RCP 8.5 and RCP 4.5 on the capacity of Pacific Island governments to earn access fees from industrial tuna fishing, and the contributions of these access fees to total government revenue excluding grants ('government revenue'), we used annual averages of government revenue, tuna-fishing access fees earned by the ten Pacific SIDS and the percentage contribution of access fees to government revenue for the period 2015-2018 (Supplementary Table 2) as a baseline. We applied the projected average percentage changes in total purse-seine catch in each EEZ for RCP 8.5 and RCP 4.5 (summarized in Supplementary Tables 17 and 18) to the average annual access fees received in 2015-2018 by each of the Pacific SIDS to estimate the change in value of their access fees by 2050 under each emissions scenario. The change in value of access fees was used to estimate decreases or increases in government revenue in 2050 relative to 2015-2018 under both emissions scenarios in US\$ and percentage terms, assuming that the relative contributions of other sources of government revenue remain the same.

The estimated percentage changes in government revenue for each Pacific SIDS do not account for (1) management responses; (2) variation in the value of access to particular EEZs and the willingness of fleets to pay for this access due to the effects of changes in tuna biomass on catchability of each species, levels of fishing effort/catch rates, the price of tuna or cost of landing tuna; and (3) the impact of tuna redistribution on the degree of control that Pacific SIDS exert over fisheries targeting tuna. The third factor is expected to be particularly important. For example, substantial movement of tuna from the EEZs of PNA countries into high-seas areas would be expected to limit the effectiveness of the VDS ${ }^{69}$ by reducing the degree of control over the fishery exerted by PNA members.

Overall, it is important to note that the simple approach used to assess the potential effects of tuna redistribution on government revenue is intended only to provide indicative information on the magnitude of these impacts. To obtain robust estimates of climate-driven changes in government revenue, more complex bio-economic analyses will be required, beginning with, for example, a fleet-dynamics analysis to investigate the potential response of purse-seine vessels to redistribution of tuna and the flow-on effects on access fees.

Reporting Summary. Further information on research design is available in the Nature Research Reporting Summary linked to this article.

\section{Data availability}

The 3D ocean data from the ESMs in netcdf format used to inform the SEAPODYM modelling are available at http://data.umr-lops.fr/pub/AFCM85/. All analysed data on tuna catch and government revenue are included in the published Analysis and the Supplementary Information files.

\section{Code availability}

The executable files for SEAPODYM, together with the input files, the outputs and the SEAPODYM manual, are available on a repository at https://osf.io/qa8w4/.

Received: 19 November 2020; Accepted: 15 June 2021; Published online: 29 July 2021

\section{References}

1. Economic and Development Indicators and Statistics: Tuna Fisheries of the Western and Central Pacific Ocean (Pacific Islands Forum Fisheries Agency, 2017).
2. Bell, J. D. et al. Diversifying the use of tuna for food security and public health in Pacific Island countries and territories. Mar. Policy 51, 584-591 (2015).

3. Regional Roadmap for Sustainable Pacific Fisheries (Pacific Islands Forum Fisheries Agency and Pacific Community, 2015)

4. Hare, S. R. et al. The Western and Central Pacific Tuna Fishery: 2019 Overview and Status of Stocks Tuna Fisheries Assessment Report No. 20 (Pacific Community, 2020).

5. Lehodey, P., Bertignac, M., Hampton, J., Lewis, A. \& Picaut, J. El NiñoSouthern Oscillation and tuna in the western Pacific. Nature 389, 715-718 (1997).

6. Lehodey, P. et al. in Vulnerability of Tropical Pacific Fisheries and Aquaculture to Climate Change (eds Bell, J. D. et al.) Ch. 8 (Secretariat of the Pacific Community, 2011).

7. Cai, W. et al. Increasing frequency of extreme El Niño events due to greenhouse warming. Nat. Clim. Change 4, 111-116 (2014).

8. Cai, W. et al. ENSO and greenhouse warming. Nat. Clim. Change 5, 849-859 (2015).

9. Bell, J. D., Johnson, J. E. \& Hobday, A. J. (eds) Vulnerability of Tropical Pacific Fisheries and Aquaculture to Climate Change (Secretariat of the Pacific Community, 2011).

10. Bell, J. D. et al. Mixed responses of tropical Pacific fisheries and aquaculture to climate change. Nat. Clim. Change 3, 591-599 (2013).

11. Bell, J. D. et al. in Impacts of Climate Change on Fisheries and Aquaculture: Synthesis of Current Knowledge, Adaptation and Mitigation Options (eds Barange, M. et al.) Ch. 14 (FAO, 2018).

12. Lehodey, P., Senina, I., Calmettes, B., Hampton, J. \& Nicol, S. Modelling the impact of climate change on Pacific skipjack tuna population and fisheries. Climatic Change 119, 95-109 (2013).

13. Senina, I. et al. Impact of Climate Change on Tropical Pacific Tuna and Their Fisheries in Pacific Islands Waters and High Seas Areas Working Paper WCPFC-SC14-2018/ EB-WP-01 (WCPFC Scientific Committee, 2018).

14. Implications of Climate-Driven Redistribution of Tuna on Pacific Island Economies Policy Brief 32/2019 (Pacific Community, 2019).

15. Lehodey, P., Senina, I. \& Murtugudde, R. A spatial ecosystem and population dynamics model (SEAPODYM)-modelling of tuna and tuna-like populations. Prog. Oceanogr. 78, 304-318 (2008).

16. Lehodey, P., Murtugudde, R. \& Senina, I. Bridging the gap from ocean models to population dynamics of large marine predators: a model of mid-trophic functional groups. Prog. Oceanogr. 84, 69-84 (2010).

17. Senina, I., Sibert, J. \& Lehodey, P. Parameter investigation for basin-scale ecosystem-linked population models of large pelagic predators: application to skipjack tuna. Prog. Oceanogr. 78, 319-335 (2008).

18. McNamara, K. E. et al. An assessment of community-based adaptation initiatives in the Pacific Islands. Nat. Clim. Change 10, 628-639 (2020).

19. Pecl, G. T. et al. Biodiversity redistribution under climate change: impacts on ecosystems and human well-being. Science 355, eaai9214 (2017).

20. Lam, V. W. Y. et al. Climate change, tropical fisheries and prospects for sustainable development. Nat. Rev. Earth Environ. 1, 440-454 (2020).

21. Towards the Quantification of Illegal, Unreported and Unregulated (IUU) Fishing in the Pacific Islands Region (MRAG Asia Pacific, 2016).

22. Pinsky, M. L. et al. Preparing ocean governance for species on the move. Science 360, 1189-1191 (2018)

23. Oremus, K. L. et al. Governance challenges for tropical nations losing fish species due to climate change. Nat. Sustain. 3, 277-280 (2020).

24. United Nations General Assembly Resolution 72/249 (UNGA, 2017).

25. Quirk, G. C. \& Harden-Davies, H. R. Cooperation, competence and coherence: the role of regional ocean governance in the south west Pacific for the conservation and sustainable use of biodiversity beyond national jurisdiction. Int. J. Mar. Coast. Law 32, 672-708 (2017).

26. Haas, B., Haward, M., McGee, J. \& Fleming, A. Regional fisheries management organizations and the new biodiversity agreement: challenge or opportunity? Fish Fish. 22, 226-231 (2021).

27. Tladi, D. The proposed implementing agreement: options for coherence and consistency in the establishment of protected areas beyond national jurisdiction. Int. J. Mar. Coast. Law. 30, 654-673 (2015).

28. Friedman, A. Beyond 'not undermining': possibilities for global cooperation to improve environmental protection in areas beyond national jurisdiction. ICES J. Mar. Sci. 76, 452-456 (2019).

29. Robinson, M. Climate Justice (Bloomsbury, 2018).

30. Robinson, M. \& Shine, T. Achieving a climate justice pathway to $1.5^{\circ} \mathrm{C}$. Nat. Clim. Change 8, 564-569 (2018).

31. Cheung, W. W. L., Reygondeau, G. \& Frölicher, T. L. Large benefits to marine fisheries of meeting the $1.5^{\circ} \mathrm{C}$ global warming target. Science 354, 1591-1594 (2016).

32. Convention on the Conservation and Management of Highly Migratory Fish Stocks in the Western and Central Pacific Ocean (WCPFC, 2004).

33. Agreement for the Implementation of the Provisions of the United Nations Convention on the Law of the Sea of 10 December 1982 Relating to the 
Conservation and Management of Straddling Fish Stocks and Highly Migratory Fish Stocks (UNFSA, 1995)

34. CMM 2018-01: Conservation and Management Measure for Bigeye, Yellowfin and Skipjack Tuna in the Western and Central Pacific Ocean (WCPFC, 2018).

35. Seto, K. et al. Resource allocation in transboundary tuna fisheries: a global analysis. Ambio 50, 242-259 (2021).

36. Report of the Sixteenth Regular Session of the Western and Central Pacific Fisheries Commission (WCPFC, 2019).

37. Gardiner, S. M. in The Oxford Handbook of Climate Change and Society (eds Dryzek, J. S. et al.) 309-322 (Oxford Univ. Press, 2011)

38. Pellow, D. N. What is Critical Environmental Justice? (Wiley, 2017).

39. Mikulewicz, M. Politicizing vulnerability and adaptation: on the need to democratize local responses to climate impacts in developing countries. Clim. Dev. 10, 18-34 (2018)

40. Meehl, G. A., Hu, A. \& Teng, H. Initialized decadal prediction for transition to positive phase of the Interdecadal Pacific Oscillation. Nat. Commun. 7, 11718 (2016)

41. Grewe, P. M. et al. Evidence of discrete yellowfin tuna (Thunnus albacares) populations demands rethink of management for this globally important resource. Sci. Rep. 5, 16916 (2015).

42. Anderson, G., Lal, M., Hampton, J., Smith, N. \& Rico, C. Close kin proximity in yellowfin tuna (Thunnus albacares) as a driver of population genetic structure in the tropical western and central Pacific Ocean. Front. Mar. Sci. 6 , 341 (2019).

43. Moore, B. R. et al. Defining the stock structures of commercial tunas in the Pacific Ocean I: current knowledge and key uncertainties. Fish. Res. 230, 105525 (2020)

44. Moore, B. R. et al. Defining the stock structures of commercial tunas in the Pacific Ocean II: sampling considerations and future directions. Fish. Res. 230, 105524 (2020).

45. Gaines, S. D. et al. Improved fisheries management could offset many negative effects of climate change. Sci. Adv. 4, eaao1378 (2018).

46. Madec, G. et al. NEMO ocean engine. Zenodo https://doi.org/10.5281/ zenodo.3248739 (2017)

47. Aumont, O., Ethé, C., Tagliabue, A., Bopp, L. \& Gehlen, M. PISCES-v2: an ocean biogeochemical model for carbon and ecosystem studies. Geosci. Model Dev. 8, 2465-2513 (2015).

48. Lee, Y. J. et al. Net primary productivity estimates and environmental variables in the Arctic Ocean: an assessment of coupled physicalbiogeochemical models. J. Geophys. Res. Oceans 121, 8635-8669 (2016).

49. Dussin, R., Barnier, B. \& Brodeau, L. The Making of Drakkar Forcing Set DFS5 DRAKKAR/MyOcean Report 05-10-14 (Drakkar International Research Network, 2014).

50. Garcia, H. E. et al. World Ocean Atlas 2009, Volume 4: Nutrients (Phosphate, Nitrate, Silicate) (US Government Printing Office, 2010).

51. Menkes, C. E. et al. Global impact of tropical cyclones on primary production. Glob. Biogeochem. Cycles 30, 767-786 (2016).

52. Nicol, S. et al. Oceanographic characterisation of the Pacific Ocean and the potential impact of climate variability on tuna stocks and tuna fisheries. SPC Fish. Newsl. 145, 37-48 (2014).

53. Taylor, K. E., Stouffer, R. J. \& Meehl, G. A. An overview of CMIP5 and the experiment design. Bull. Am. Meteorol. Soc. 93, 485-498 (2012).

54. Bellenger, H., Guilyardi, E., Leloup, J., Lengaigne, M. \& Vialard, J. ENSO representation in climate models: from CMIP3 to CMIP5. Clim. Dynam. 42, 1999-2018 (2014)

55. Dufresne, J.-L. et al. Climate change projections using the IPSL-CM5 Earth system model: from CMIP3 to CMIP5. Clim. Dynam. 40, 2123-2165 (2013).

56. Watanabe, S. et al. MIROC-ESM 2010: model description and basic results of CMIP5-20c3m experiments. Geosci. Model Dev. 4, 845-872 (2011).

57. Dunne, J. P. et al. GFDL's ESM2 global coupled climate-carbon Earth system models. Part I: physical formulation and baseline simulation characteristics. J. Clim. 25, 6646-6665 (2012).

58. Mauritsen, T. et al. Tuning the climate of a global model. J. Adv. Model. Earth Syst. https://doi.org/10.1029/2012MS000154 (2012).

59. Brown, J. R. et al. South Pacific Convergence Zone dynamics, variability and impacts in a changing climate. Nat. Rev. Earth Environ. 1, 530-543 (2020)

60. Dutheil, C. et al. Impact of surface temperature biases on climate change projections of the South Pacific Convergence Zone. Clim. Dynam. 53, 3197-3219 (2019).

61. Brown, J. N., Langlais, C. \& Maes, C. Zonal structure and variability of the Western Pacific dynamic warm pool edge in CMIP5. Clim. Dynam. 42, 3061-3076 (2014)

62. Lehodey, P. et al. Optimization of a micronekton model with acoustic data. ICES J. Mar. Sci. 72, 1399-1412 (2015)

63. Lehodey, P. et al. Modelling the Impact of Climate Change Including Ocean Acidification on Pacific Yellowfin Tuna Working Paper WCPFC- SC13-2017/ EB-WP-01 (WCPFC Scientific Committee, 2017).
64. Senina, I., Lehodey, P., Hampton, J. \& Sibert, J. Quantitative modelling of the spatial dynamics of South Pacific and Atlantic albacore tuna populations. Deep Sea Res. II 175, 104667 (2020).

65. Senina, I., Lehodey, P., Sibert, J. \& Hampton, J. Integrating tagging and fisheries data into a spatial population dynamics model to improve its predictive skills. Can. J. Aquat. Fish. Sci. 77, 576-593 (2020).

66. Lehodey, P. et al. Preliminary forecasts of population trends for Pacific bigeye tuna under the A2 IPCC scenario. Prog. Oceanogr. 86, 302-315 (2010).

67. Lehodey, P., Senina, I., Nicol, S. \& Hampton, J. Modelling the impact of climate change on South Pacific albacore tuna. Deep Sea Res. II 113, 246-259 (2015).

68. Herger, N., Sanderson, B. M. \& Knutti, R. Improved pattern scaling approaches for the use in climate impact studies. Geophys. Lett. 42, 3486-3494 (2015).

69. Aqorau, T. Recent developments in Pacific tuna fisheries: the Palau Arrangement and the Vessel Day Scheme. Int. J. Mar. Coast. Law 24, 557-581 (2009)

70. Clark, S. et al. in Adaptive Management of Fisheries in Response to Climate Change Fisheries and Aquaculture Technical Paper 667 (eds Bahri, T. et al.) Ch. 12 (FAO, 2021).

71. Aqorau, T., Bell, J. \& Kittinger, J. N. Good governance for migratory species. Science 361, 1208-1209 (2018)

\section{Acknowledgements}

This article is dedicated to our co-author Sue Taei, who lost her battle with cancer recently. Sue was a regional thought leader and was instrumental in helping to design this study and obtain the resources needed to extend the tuna modelling from exclusive economic zones to high-seas areas to examine the implications for Pacific Island economies. We thank T. Ruaia for providing data on access fees; C. Appel, B. Colas, A. Desurmont and E. Johansen for assistance with figures; and P. Gardiner, S. Kay, J. Kittinger and P. Obregon for helpful discussions/comments on the draft manuscript. J.D.B., I.S. and P.L. thank the Moccasin Lake Foundation and the GEF-funded, World Bank-implemented Ocean Partnerships for Sustainable Fisheries and Biodiversity Conservation, a sub-project of the Common Oceans ABNJ Program led by UN-FAO, for financial support for this research and preparation of this article. SEAPODYM simulations were also partially funded from the European Union's Horizon 2020 research and innovation programme COMFORT, under grant agreement no. 820989 (noting that the European Commission and their executive agency are not responsible for any use that may be made of the information from the simulations). Q.H., H.H.-D., Y.O. and K.L.S. acknowledge support from the Nippon Foundation Ocean Nexus Center at the University of Washington Earthlab.

\section{Author contributions}

J.D.B., T.A., Q.H., H.H.-D., G.H., W.M., C.P., Y.O., K.L.S., N.S., S.T. and M.T. designed the study during a workshop at the University of Wollongong. O.A., B.C., M.D., M.G., T.G., M.L. and C.M. produced the ocean forcings, and I.S. and P.L. modelled the responses of tuna to ocean warming with SEAPODYM. J.D.B. compiled the main text and Supplementary Information on the basis of contributions from all authors.

\section{Competing interests}

The authors declare no competing interests.

\section{Additional information}

Supplementary information The online version contains supplementary material available at https://doi.org/10.1038/s41893-021-00745-z.

Correspondence and requests for materials should be addressed to J.D.B.

Peer review information Nature Sustainability thanks Liam Campling, Kevern Cochrane and the other, anonymous, reviewer(s) for their contribution to the peer review of this work.

Reprints and permissions information is available at www.nature.com/reprints.

Publisher's note Springer Nature remains neutral with regard to jurisdictional claims in published maps and institutional affiliations.

Open Access This article is licensed under a Creative Commons Attribution 4.0 International License, which permits use, sharing, adaptation, distribution and reproduction in any medium or format, as long as you give appropriate credit to the original author(s) and the source, provide a link to the Creative Commons license, and indicate if changes were made. The images or other third party material in this article are included in the article's Creative Commons license, unless indicated otherwise in a credit line to the material. If material is not included in the article's Creative Commons license and your intended use is not permitted by statutory regulation or exceeds the permitted use, you will need to obtain permission directly from the copyright holder. To view a copy of this license, visit http://creativecommons.org/licenses/by/4.0/.

(C) The Author(s) 2021 


\section{Reporting Summary}

Nature Research wishes to improve the reproducibility of the work that we publish. This form provides structure for consistency and transparency in reporting. For further information on Nature Research policies, see our Editorial Policies and the Editorial Policy Checklist.

\section{Statistics}

For all statistical analyses, confirm that the following items are present in the figure legend, table legend, main text, or Methods section.

n/a Confirmed

$\square$ The exact sample size $(n)$ for each experimental group/condition, given as a discrete number and unit of measurement

$\square \square$ A statement on whether measurements were taken from distinct samples or whether the same sample was measured repeatedly

$\square$ The statistical test(s) used AND whether they are one- or two-sided

$\square$ Only common tests should be described solely by name; describe more complex techniques in the Methods section.

$\square \square$ A description of all covariates tested

$\square$ A description of any assumptions or corrections, such as tests of normality and adjustment for multiple comparisons

$\square$ A full description of the statistical parameters including central tendency (e.g. means) or other basic estimates (e.g. regression coefficient)

AND variation (e.g. standard deviation) or associated estimates of uncertainty (e.g. confidence intervals)

For null hypothesis testing, the test statistic (e.g. $F, t, r$ ) with confidence intervals, effect sizes, degrees of freedom and $P$ value noted Give $P$ values as exact values whenever suitable.

$\square$ For Bayesian analysis, information on the choice of priors and Markov chain Monte Carlo settings

$\square \square$ For hierarchical and complex designs, identification of the appropriate level for tests and full reporting of outcomes

Estimates of effect sizes (e.g. Cohen's $d$, Pearson's $r$ ), indicating how they were calculated

Our web collection on statistics for biologists contains articles on many of the points above.

\section{Software and code}

Policy information about availability of computer code

Data collection The executable files for SEAPODYM with the pre-defined model configurations, and all the input files to generate model output data, are available at https://osf.io/qa8w4/

Data analysis This study involves model simulations and analysis of model outputs. The simulations done with custom SEAPODYM software written in C++, and all data processing and algorithms for the model output analyses developed using R programming language and $\mathrm{R}$ open source software, are available at https://osf.io/qa8w4/

For manuscripts utilizing custom algorithms or software that are central to the research but not yet described in published literature, software must be made available to editors and reviewers. We strongly encourage code deposition in a community repository (e.g. GitHub). See the Nature Research guidelines for submitting code \& software for further information.

\section{Data}

Policy information about availability of data

All manuscripts must include a data availability statement. This statement should provide the following information, where applicable:

- Accession codes, unique identifiers, or web links for publicly available datasets

- A list of figures that have associated raw data

- A description of any restrictions on data availability

Raw data were generated by the Earth System Models and the SEAPODYM ecosystem model described in the Methods.

The 3-D ocean data from the Earth System Models in netcdf format are available at http://data.umr-lops.fr/pub/AFCM85/

The 2-D forcing input data files for SEAPODYM, and the output data files to reproduce the results are available at https://osf.io/qa8w4/

The spreadsheets used to produce Supplementary Tables 5-20 are available at https://osf.io/qa8w4/ 


\section{Field-specific reporting}

Please select the one below that is the best fit for your research. If you are not sure, read the appropriate sections before making your selection.

Life sciences

Behavioural \& social sciences

Ecological, evolutionary \& environmental sciences

For a reference copy of the document with all sections, see nature.com/documents/nr-reporting-summary-flat.pdf

\section{Ecological, evolutionary \& environmental sciences study design}

All studies must disclose on these points even when the disclosure is negative.

Study description

Research sample

Sampling strategy

Data collection

Timing and spatial scale

Data exclusions

Reproducibility

Randomization

Blinding

This study was designed to use the latest improvements to the SEAPODYM model, and the best available ocean forcings, to project the redistribution of tuna caught by purse-seine fishing from the exclusive economic zones (EEZs) of Pacific Island countries to highseas areas in the western and central Pacific Ocean (WCPO) and the eastern Pacific Ocean (EPO) under a range of IPCC greenhouse gas emissions scenarios by 2050. The modeling outputs were used to estimate 1 ) changes in the average tuna catch from each EEZ and from 14 high-seas areas in the WCPO and EPO in 2050, and 2) the effects of changes in tuna catches on the future government revenue of 10 tuna-dependent Pacific Island countries.

The existing datasets used in this study include: 1) the annual combined purse-seine catch of skipjack, yellowfin and bigeye tuna from the EEZs of Pacific Island countries and high-seas areas, for the 10-year period 2009-2018, which is held by the Oceanic Fisheries Programme at The Pacific Community (SPC) (www.spc.int); and 2) the annual value of tuna-fishing licence revenue (access fees) earned by Pacific Island countries, total annual (non-aid) government revenue earned by Pacific Island countries, and the proportion of government revenue derived from tuna-fishing access fees each year for the 4-year period 2015-2018, which is held by the Pacific Islands Forum Fisheries Agency (FFA) (www.ffa.int).

\section{No dislosure to be made}

Data on tuna catch were provided to SPC by fishing fleets using well-established protocols. Data on tuna-fishing access fees and total (non-aid) government revenue received by Pacific Island countries, were provided to FFA by these countries.

The data used to estimate the average annual catch of all tuna caught by purse-seine were collected between January 2009 and December 2018 across the expanse of the tropical Pacific Ocean, but mainly from the area between 20 degrees north and 20 degrees south. The combined area of the EEZs of the 10 tuna-dependent Pacific Island countries alone is more than 16 million square $\mathrm{km}$.

\section{No relevant data were excluded}

To reproduce the results of the current study based on the ocean forcings available at http://data.umr-lops.fr/pub/AFCM85/, the model simulations can be run using SEAPODYM software under designed configurations. The configurations used in this study were obtained from studies published or reported elsewhere, and founded on a quantitative approach, including model parameterisations based on the maximum likelihood estimation method, validation and error analysis.

No dislosure to be made

No dislosure to be made

Did the study involve field work? $\square$ Yes $\$ No

\section{Reporting for specific materials, systems and methods}

We require information from authors about some types of materials, experimental systems and methods used in many studies. Here, indicate whether each material, system or method listed is relevant to your study. If you are not sure if a list item applies to your research, read the appropriate section before selecting a response. 
Materials \& experimental systems

\begin{tabular}{l|l}
\hline n/a Involved in the study \\
$\square$ Antibodies \\
$\square$ Eukaryotic cell lines \\
$\square$ Palaeontology and archaeology \\
$\square$ Animals and other organisms \\
$\square$ Cuman research participants \\
$\square$ Clinical data \\
$\square$ Dual use research of concern
\end{tabular}

Methods

n/a Involved in the study

$\square \square$ ChIP-seq

$\square \square$ Flow cytometry

$\square \mid \square$ MRI-based neuroimaging

\section{Antibodies}

Antibodies used

Validation
Describe all antibodies used in the study; as applicable, provide supplier name, catalog number, clone name, and lot number.

Describe the validation of each primary antibody for the species and application, noting any validation statements on the manufacturer's website, relevant citations, antibody profiles in online databases, or data provided in the manuscript.

\section{Eukaryotic cell lines}

Policy information about cell lines

Cell line source(s)

State the source of each cell line used.

Authentication

Describe the authentication procedures for each cell line used OR declare that none of the cell lines used were authenticated.

Mycoplasma contamination

Confirm that all cell lines tested negative for mycoplasma contamination OR describe the results of the testing for mycoplasma contamination OR declare that the cell lines were not tested for mycoplasma contamination.

Commonly misidentified lines

(See ICLAC register)

Name any commonly misidentified cell lines used in the study and provide a rationale for their use.

\section{Palaeontology and Archaeology}

Specimen provenance Provide provenance information for specimens and describe permits that were obtained for the work (including the name of the issuing authority, the date of issue, and any identifying information).

Specimen deposition

Indicate where the specimens have been deposited to permit free access by other researchers.

Dating methods

If new dates are provided, describe how they were obtained (e.g. collection, storage, sample pretreatment and measurement), where they were obtained (i.e. lab name), the calibration program and the protocol for quality assurance OR state that no new dates are provided.

Tick this box to confirm that the raw and calibrated dates are available in the paper or in Supplementary Information.

Ethics oversight

Identify the organization(s) that approved or provided guidance on the study protocol, OR state that no ethical approval or guidance was required and explain why not.

Note that full information on the approval of the study protocol must also be provided in the manuscript.

\section{Animals and other organisms}

Policy information about studies involving animals; ARRIVE guidelines recommended for reporting animal research

Laboratory animals

For laboratory animals, report species, strain, sex and age OR state that the study did not involve laboratory animals.

Wild animals

Provide details on animals observed in or captured in the field; report species, sex and age where possible. Describe how animals were caught and transported and what happened to captive animals after the study (if killed, explain why and describe method; if released, say where and when) OR state that the study did not involve wild animals.

Field-collected samples For laboratory work with field-collected samples, describe all relevant parameters such as housing, maintenance, temperature, photoperiod and end-of-experiment protocol OR state that the study did not involve samples collected from the field.

Ethics oversight

Identify the organization(s) that approved or provided guidance on the study protocol, OR state that no ethical approval or guidance was required and explain why not.

Note that full information on the approval of the study protocol must also be provided in the manuscript. 
Policy information about studies involving human research participants

Population characteristics

Describe the covariate-relevant population characteristics of the human research participants (e.g. age, gender, genotypic information, past and current diagnosis and treatment categories). If you filled out the behavioural \& social sciences study design questions and have nothing to add here, write "See above."

Recruitment

Describe how participants were recruited. Outline any potential self-selection bias or other biases that may be present and how these are likely to impact results.

Ethics oversight

Identify the organization(s) that approved the study protocol.

Note that full information on the approval of the study protocol must also be provided in the manuscript.

\section{Clinical data}

Policy information about clinical studies

All manuscripts should comply with the ICMJE guidelines for publication of clinical research and a completed CONSORT checklist must be included with all submissions.

Clinical trial registration

Study protocol

Data collection

Outcomes
Provide the trial registration number from ClinicalTrials. gov or an equivalent agency.

Note where the full trial protocol can be accessed OR if not available, explain why.

Describe the settings and locales of data collection, noting the time periods of recruitment and data collection.

Describe how you pre-defined primary and secondary outcome measures and how you assessed these measures.

\section{Dual use research of concern}

Policy information about dual use research of concern

\section{Hazards}

Could the accidental, deliberate or reckless misuse of agents or technologies generated in the work, or the application of information presented in the manuscript, pose a threat to:
No Yes
$\square \square$ Public health
$\square \square$ National security
$\square \square$ Crops and/or livestock
$\square \square$ Ecosystems
$\square \square$ Any other significant area

\section{Experiments of concern}

Does the work involve any of these experiments of concern:
No $\mid$ Yes
$\square \square$ Demonstrate how to render a vaccine ineffective
$\square \square$ Confer resistance to therapeutically useful antibiotics or antiviral agents
$\square \square$ Enhance the virulence of a pathogen or render a nonpathogen virulent
$\square$ Increase transmissibility of a pathogen
$\square \square$ Alter the host range of a pathogen
$\square \square$ Enable evasion of diagnostic/detection modalities
$\square \square$ Enable the weaponization of a biological agent or toxin
$\square$ Any other potentially harmful combination of experiments and agents

\section{ChIP-seq}

\section{Data deposition}

$\square$ Confirm that both raw and final processed data have been deposited in a public database such as GEO.

$\square$ Confirm that you have deposited or provided access to graph files (e.g. BED files) for the called peaks. 
Data access links

May remain private before publication

Files in database submission

Genome browser session

(e.g. UCSC)
For "Initial submission" or "Revised version" documents, provide reviewer access links. For your "Final submission" document, provide a link to the deposited data.

Provide a list of all files available in the database submission.

Provide a link to an anonymized genome browser session for "Initial submission" and "Revised version" documents only, to enable peer review. Write "no longer applicable" for "Final submission" documents.

\section{Methodology}

Replicates

Sequencing depth

Describe the experimental replicates, specifying number, type and replicate agreement.

Antibodies

Describe the sequencing depth for each experiment, providing the total number of reads, uniquely mapped reads, length of reads and whether they were paired-or single-end.

Describe the antibodies used for the ChIP-seq experiments; as applicable, provide supplier name, catalog number, clone name, and lot number.

Peak calling parameters Specify the command line program and parameters used for read mapping and peak calling, including the ChIP, control and index files used.

Data quality

Software

Describe the methods used to ensure data quality in full detail, including how many peaks are at FDR 5\% and above 5-fold enrichment.

Describe the software used to collect and analyze the ChIP-seq data. For custom code that has been deposited into a community repository, provide accession details.

\section{Flow Cytometry}

Plots

Confirm that:

$\square$ The axis labels state the marker and fluorochrome used (e.g. CD4-FITC).

$\square$ The axis scales are clearly visible. Include numbers along axes only for bottom left plot of group (a 'group' is an analysis of identical markers).

All plots are contour plots with outliers or pseudocolor plots.

$\square$ A numerical value for number of cells or percentage (with statistics) is provided.

\section{Methodology}

Sample preparation

Describe the sample preparation, detailing the biological source of the cells and any tissue processing steps used.

Instrument

Identify the instrument used for data collection, specifying make and model number.

Software

Describe the software used to collect and analyze the flow cytometry data. For custom code that has been deposited into a community repository, provide accession details.

Cell population abundance

Describe the abundance of the relevant cell populations within post-sort fractions, providing details on the purity of the samples and how it was determined.

Gating strategy

Describe the gating strategy used for all relevant experiments, specifying the preliminary FSC/SSC gates of the starting cell population, indicating where boundaries between "positive" and "negative" staining cell populations are defined.

Tick this box to confirm that a figure exemplifying the gating strategy is provided in the Supplementary Information.

\section{Magnetic resonance imaging}

\section{Experimental design}

Design type

Design specifications

Behavioral performance measures
Indicate task or resting state; event-related or block design.

Specify the number of blocks, trials or experimental units per session and/or subject, and specify the length of each trial or block (if trials are blocked) and interval between trials.

State number and/or type of variables recorded (e.g. correct button press, response time) and what statistics were used to establish that the subjects were performing the task as expected (e.g. mean, range, and/or standard deviation across subjects). 
Acquisition

Imaging type(s)

Specify: functional, structural, diffusion, perfusion.

Field strength

Specify in Tesla

Sequence \& imaging parameters

Specify the pulse sequence type (gradient echo, spin echo, etc.), imaging type (EPI, spiral, etc.), field of view, matrix size slice thickness, orientation and TE/TR/flip angle.

Area of acquisition

State whether a whole brain scan was used OR define the area of acquisition, describing how the region was determined.

Diffusion MRI

$\square$ Used

Not used

Preprocessing

Preprocessing software

Provide detail on software version and revision number and on specific parameters (model/functions, brain extraction, segmentation, smoothing kernel size, etc.).

Normalization

If data were normalized/standardized, describe the approach(es): specify linear or non-linear and define image types used for transformation OR indicate that data were not normalized and explain rationale for lack of normalization.

Normalization template

Describe the template used for normalization/transformation, specifying subject space or group standardized space (e.g. original Talairach, MNI305, ICBM152) OR indicate that the data were not normalized.

Noise and artifact removal

Describe your procedure(s) for artifact and structured noise removal, specifying motion parameters, tissue signals and physiological signals (heart rate, respiration).

Volume censoring

Define your software and/or method and criteria for volume censoring, and state the extent of such censoring.

Statistical modeling \& inference

Model type and settings

Specify type (mass univariate, multivariate, RSA, predictive, etc.) and describe essential details of the model at the first and second levels (e.g. fixed, random or mixed effects; drift or auto-correlation).

Effect(s) tested

Define precise effect in terms of the task or stimulus conditions instead of psychological concepts and indicate whether ANOVA or factorial designs were used.

Specify type of analysis:

$\square$ Whole brain $\square$ ROl-based $\square$ Both

Statistic type for inference (See Eklund et al. 2016)

Correction

Specify voxel-wise or cluster-wise and report all relevant parameters for cluster-wise methods.

Describe the type of correction and how it is obtained for multiple comparisons (e.g. FWE, FDR, permutation or Monte Carlo).

Models \& analysis

n/a $\mid$ Involved in the study

$\square \square$ Functional and/or effective connectivity

$\square \square$ Graph analysis

$\square \square$ Multivariate modeling or predictive analysis

Functional and/or effective connectivity

Report the measures of dependence used and the model details (e.g. Pearson correlation, partial correlation, mutual information).

Graph analysis

Report the dependent variable and connectivity measure, specifying weighted graph or binarized graph, subject-or group-level, and the global and/or node summaries used (e.g. clustering coefficient, efficiency, etc.).

Multivariate modeling and predictive analysis

Specify independent variables, features extraction and dimension reduction, model, training and evaluation metrics. 